\title{
Intercomparison of dissolved iron isotope profiles from re-occupation of three GEOTRACES stations in the Atlantic Ocean
}

\author{
Conway, T. M. ${ }^{1,2, *}$, John, S. G. ${ }^{2,3}$ and Lacan, F. \\ ${ }^{1}$ Dept. Earth Sciences, ETH Zürich, Zürich, Switzerland \\ ${ }^{2}$ Dept. Earth and Ocean Sciences, University of South Carolina, Columbia, S.C., United States \\ ${ }^{3}$ Dept. of Earth Sciences, University of Southern California, Los Angeles, USA (present address) \\ ${ }^{4}$ LEGOS, Université de Toulouse, CNES, CNRS, IRD, UPS, Toulouse, France
}

*Corresponding author: conway.tm@gmail.com; Phone: Tel: +41 446324797

Keywords: trace metals, GEOTRACES, biogeochemistry, intercomparison 
3 Intercomparison of trace metal data is a key aspect of the International GEOTRACES

4 program, allowing data from multiple laboratories and countries to be combined to

5 produce high-resolution datasets for the oceans. The use of crossover stations by the

6 GEOTRACES program provides the opportunity both for comparison of analytical

7 techniques and assessment of temporal variability in the cycling of trace metals such

8 as iron $(\mathrm{Fe})$. Here, we present the first comparison of dissolved $\mathrm{Fe}$ stable isotope ratio

$9 \quad\left(\delta^{56} \mathrm{Fe}\right.$; relative to IRMM-014) profiles in the oceans, from re-occupations of three

10 locations in the Atlantic Ocean; (1) the Bermuda Atlantic Time Series Station

$11\left(31.75^{\circ} \mathrm{N} 64.17^{\circ} \mathrm{W}\right)$ during the U.S. GEOTRACES IC1 cruise (June 2008) and the

12 U.S. GEOTRACES GA03 cruise (Nov. 2011); (2) a station near Cape Verde $\left(17.4^{\circ} \mathrm{N}\right.$

$1324.5^{\circ} \mathrm{W}$ ) during the U.S GEOTRACES GA03 cruises (2010; 2011), and (3) two

14 nearby stations in the Cape Basin close to South West Africa $\left(31.1-31.4^{\circ} \mathrm{S} 36.5^{\circ} \mathrm{W}\right)$

15 during the French GEOTRACES GIPY4 Bonus Good Hope Cruise (Feb. 2008) and

16 the U.K. GEOTRACES GA10 D357 cruise (Oct. 2010). These datasets provided us

17 with the opportunity not only to compare sampling and analysis techniques by two

18 different laboratories (USC and LEGOS), but also the temporal variability of $\delta^{56} \mathrm{Fe}$ at

19 these locations on a 1-3 year timescale. A good agreement between data and profiles

20 generated by different laboratories does allows assessment of temporal variation of

$21 \delta^{56} \mathrm{Fe}$ in the water column, as well as spatial variability and synthesis of datasets from

22 different regions of the ocean. Comparison of $\delta^{56} \mathrm{Fe}$ at the three locations in this study

23 demonstrates a remarkable consistency between the shape of ocean $\delta^{56} \mathrm{Fe}$ profiles

24 measured 1-3 years apart, pointing to the overall stability of Fe cycling at all three

25 locations on these timescales, despite the expected dynamic nature of the Fe cycle.

26 This consistency is highlighted by strong agreement in $\delta^{56} \mathrm{Fe}$ throughout the whole

27 water-column at Bermuda, and in waters deeper than $500 \mathrm{~m}$ in the Cape Basin, which

28 suggests that different water masses may carry distinct $\delta^{56} \mathrm{Fe}$ signatures. In contrast to

29 the stable $\delta^{56} \mathrm{Fe}$ at these locations, we observe some apparent variability in $\delta^{56} \mathrm{Fe}$

30 between cruises at other locations, both throughout the water column at Cape Verde,

31 and in Agulhas-leakage influenced surface waters in the Cape Basin. Such variability

32 may provide information about changes in internal Fe cycling or external Fe sources

33 on these timescales. Overall, this study highlights the usefulness of repeat $\delta^{56} \mathrm{Fe}$ 
measurements to provide information on the variability of Fe cycling throughout the oceans.

\section{Introduction}

Seawater dissolved iron $(\mathrm{Fe})$ is an important limiting nutrient for phytoplankton over much of the surface oceans (Moore et al., 2001). Understanding the global distribution and biogeochemical cycling of $\mathrm{Fe}$ is a central aim of the international GEOTRACES program which seeks to measure global distributions of a range of trace elements and their isotopes. Fe concentrations are a GEOTRACES key parameter, meaning their analysis is required on all GEOTRACES cruises (Anderson and Henderson, 2005; Henderson et al., 2007). Fe stable isotopes $\left(\delta^{56} \mathrm{Fe}\right)$ have been measured on several GEOTRACES cruises, although they are not a key parameter. The resulting ocean sections of dissolved Fe concentration from the Atlantic, Indian and Pacific Oceans, and similar sections in progress, are beginning to provide new insights into the marine sources, sinks and cycling of $\mathrm{Fe}$ at both the regional and global scale throughout the oceans (e.g. Conway and John, 2014a; Klunder et al., 2012; Nishioka et al., 2013; Resing et al., 2015; Rijkenberg et al., 2014; Saito et al., 2013).

GEOTRACES cruises all follow internationally agreed methods for clean sampling and handling (The GEOTRACES Cookbook; Cutter et al., 2010; 2014), meaning that datasets can be collated to form regional and global pictures of the distribution of trace metals and their isotopes in the ocean. Recently, such data as been combined to form the GEOTRACES Intermediate Data Product and the GEOTRACES eAtlas (Mawji et al., 2015; Schlitzer, 2015). To ensure compatibility of datasets from different groups and nations, given the range of collection and analytical techniques deployed on different cruises, it is essential to carry out intercomparison of data collected from the same location and/or in the same samples by multiple groups. Accordingly, intercomparison is an important aspect of the GEOTRACES program, with the recommended reporting of measurements of SAFe reference standards for dissolved trace metal concentrations, the use of cross-over stations for comparison between different GEOTRACES cruises (see Fig. 1), and a number of studies comparing sampling systems (Cutter, 2013). Inter-comparison of trace metal 
concentrations and stable isotope ratios was a goal of two U.S. GEOTRACES cruises in the Atlantic (IC1, June 2008) and North Pacific (IC2, May 2009) Oceans (Boyle et al., 2012; Cutter and Bruland, 2012; Cutter, 2013; and others), and recent work has compared the clean sampling system of the Dutch and US GEOTRACES programs as well as different analytical techniques (Middag et al., 2015).

The GEOTRACES program and similar cruises have also facilitated the application of dissolved $\mathrm{Fe}$ isotope ratios $\left(\delta^{56} \mathrm{Fe}\right)$ as a useful parameter for understanding the marine Fe cycle. Although a challenging measurement, due to the low concentration of Fe in seawater and the difficulties of analysis, advancement in chemical techniques and high-resolution mass spectrometry has allowed a number of groups to develop methods to measure seawater-dissolved $\delta^{56} \mathrm{Fe}$ over the full range of observed oceanic dissolved Fe concentrations $\left(\sim 0.02\right.$ to $\left.>2 \mathrm{nmol} \mathrm{kg}{ }^{-1}\right)$. These methods have utilized either NTA or Nobias PA-1 chelating resins (Boyle et al., 2012; Conway et al., 2013; John and Adkins, 2010; Lacan et al., 2010, 2008; Rouxel and Auro, 2010), extraction with dithiocarbamate (Ellwood et al., 2014) or co-precipitation with magnesium (de Jong et al., 2007), followed by analysis with multicollector Inductively Coupled Plasma Mass Spectrometry (MC-ICPMS). Such methods have to date led to the publication of dissolved $\delta^{56} \mathrm{Fe}$ depth profiles from a number of ocean basins (e.g. Chever et al., 2015; John and Adkins, 2012; John et al., 2012; Labatut et al., 2014; Lacan et al., 2008; Radic et al., 2011; Staubwasser et al., 2013), and a high resolution ocean section of dissolved $\delta^{56} \mathrm{Fe}$ across the North Atlantic (Conway and John, 2014a). Dissolved $\delta^{56} \mathrm{Fe}$ measurements were also part of the focus of a previous intercomparison effort utilizing seawater collected from the Bermuda Atlantic Time Series onboard the U.S GEOTRACES 1C1 cruise in 2008, where four different laboratories demonstrated strong agreement on both surface and deep water samples at concentrations of 0.4 and $0.8 \mathrm{nmol} \mathrm{kg}{ }^{-1}$ (Boyle et al., 2012; see Fig. 2c-d).

Different marine sources of $\mathrm{Fe}$ have different $\delta^{56} \mathrm{Fe}$ signatures, and these isotope signatures have been used to trace $\mathrm{Fe}$ as it mixes through the oceanic water column, including non-reductive sediment dissolution (Labatut et al., 2014; Radic et al., 2011), reductive sediment dissolution (Chever et al., 2015, John et al., 2012), and Fe from multiple sources (Conway and John, 2014a). As such, studies of seawaterdissolved $\delta^{56} \mathrm{Fe}$ show promise for understanding the cycling and differing sources of 
102 Fe to the ocean; however, application of this tracer is still limited to a small number of

103 laboratories. Thus, spatial coverage of $\delta^{56} \mathrm{Fe}$ measurements throughout the oceans

104 remains sparse. Additionally, although changing conditions over time are important to

105 our understanding of changes in Fe sources and cycling, logistics and cost have meant

106 that repeat-sampling to assess temporal variability has rarely been carried out.

107 However, re-occupation of crossover stations as part of the GEOTRACES program

108 provides us with the opportunity to begin to address this lack of knowledge of

109 variability, as well as to compare sampling and analysis by different groups.

110

111 Here we compare measured $\mathrm{Fe}$ and $\delta^{56} \mathrm{Fe}$ profiles from three locations in the Atlantic

112 Ocean (Fig. 1): 1) Occupation of a GEOTRACES crossover station at the Bermuda 113 Atlantic Time Series (BATS; $31.75^{\circ} \mathrm{N} 64.17^{\circ} \mathrm{W}$; Fig. $2 \mathrm{a}$ ) by the U.S. GEOTRACES

114 1C1 cruise in June 2008 and the U.S. GEOTRACES GA03 KN204 cruise in Nov.

1152011 (Superstation USGT11-10) allows us to compare $\delta^{56} \mathrm{Fe}$ data measured by 116 Conway and John (U.S.C.; GA03; Conway and John, 2014a) with $\delta^{56} \mathrm{Fe}$ data 117 measured by five laboratories on the IC1 cruise (Boyle et al., 2012). 2) Re-occupation 118 of the Tenatso Time Series station near Cape Verde $\left(17.4^{\circ} \mathrm{N} 24.5^{\circ} \mathrm{W}\right)$ by the 2010 119 (KN204) and 2011 (KN199) cruises of the U.S. GEOTRACES GA03 section 120 (USGT10-12 in Nov. 2010, USGT11-24 in Dec. 2011; Fig. 3a) allow us to compare $121 \delta^{56} \mathrm{Fe}$ profiles at this location a year apart. 3) Occupation of a GEOTRACES 122 crossover station in the South Atlantic by the U.K. GEOTRACES GA10 D357 Cruise 123 in 2010 (Superstation $3 ; 31.4^{\circ} \mathrm{S} 36.5^{\circ} \mathrm{W}$ ) and the French GEOTRACES GIPY4 Bonus 124 Good Hope Cruise in 2008 (Superstation S1; $31.1^{\circ} \mathrm{S} 36.5^{\circ} \mathrm{W}$ ) allow us to compare $125 \delta^{56} \mathrm{Fe}$ profiles from nearby locations three years apart (Fig. 4a), measured using 126 different collection and analytical techniques by Conway and John (GA10; USC) and 127 Lacan (GIPY4; LEGOS). Interpretation of the $\delta^{56} \mathrm{Fe}$ profiles measured at these 128 locations is the focus of other articles (Abadie et al., in review; Conway and John, 129 2014a; John and Adkins, 2012), and so here we instead focus largely on 130 intercomparison and assessment of temporal variability of $\mathrm{Fe}$ and $\delta^{56} \mathrm{Fe}$.

\section{Materials and Methods}

\subsection{Seawater collection and handling}


138 Seawater collection and sampling were previously described for these cruises by 139 Boyle et al. (2012) and Conway and John (2014a), but are briefly summarized here 140 for ease of reference. Clean seawater was collected similarly on all three U.S. 141 GEOTRACES cruises (IC1, KN199, KN204) onboard the RV Knorr, using either 142 underway Teflon towed-fish (surface samples; 2 m; Cutter and Bruland, 2012) or the 143 U.S. GEOTRACES rosette with 24x12 L GO-Flo bottles on a Kevlar cable (Cutter 144 and Bruland, 2012). Following collection, the GO-Flo bottles were transferred to a 145 clean van and the water filtered through $0.45 \mu \mathrm{m}$ Osmonics cartridge filters (towed146 fish samples) or $0.2 \mu \mathrm{m}$ Pall Acropak capsule filters (GO-Flo samples).

148 As part of IC1 at the BATS station $\left(31.75^{\circ} \mathrm{N} 64.17^{\circ} \mathrm{W}\right.$; Figs $\left.1-2\right)$ on June $22^{\text {nd }} 2008$, a $149500 \mathrm{~L}$ surface isotope sample (GSI) was pumped from the towed-fish and filtered into 150 a clean $500 \mathrm{~L}$ acid-cleaned polyethylene tank, where it was acidified with the 151 equivalent of $1 \mathrm{~mL} 12$ M HCL per litre (Boyle et al., 2012; John and Adkins, 2012). 152 Similarly a $250 \mathrm{~L}$ deep isotope sample (GDI) was collected from $2000 \mathrm{~m}$ using the 153 GEOTRACES rosette, filtered and then homogenized and acidified in an identical 154 polyethylene tank (Boyle et al., 2012). An 8 point profile for isotope comparison 155 (GPri) from depths of 75-3500 $\mathrm{m}$ and a single sample for Fe isotope measurement at $1564200 \mathrm{~m}$ were also collected using the GEOTRACES rosette and similarly filtered and 157 acidified (Boyle et al., 2012; John and Adkins, 2012). Supporting oceanographic 158 parameters were made shipboard and are taken from John and Adkins (2012).

159

160 As part of the GA03 section cruises, seawater samples were collected using towed161 fish or GEOTRACES Rosette and water filtered into $1 \mathrm{~L}$ acid-cleaned Nalgene low 162 density polyethylene (LDPE) bottles from: 1) Station USGT10-12 (17.40 ${ }^{\circ} \mathrm{N} 24.50^{\circ} \mathrm{W}$; 16325 point profile, $2-3498 \mathrm{~m}$ ) on the $02 / 11 / 2010$; 2) Superstation USGT11-12 at the 164 BATS station $\left(31.75^{\circ} \mathrm{N}, 37\right.$ point profile $\left.2-4526 \mathrm{~m}\right)$ on November $19^{\text {th }}-21^{\text {st }} 2011$; and 165 3) Station USGT11-24 (17.40 ${ }^{\circ} \mathrm{N} 24.50^{\circ} \mathrm{W}$; 25 point profile, 2-3517 $\left.\mathrm{m}\right)$ on December $1669^{\text {th }}-10^{\text {th }} 2011$. (Figs $1-3$ ). Seawater samples were acidified back on shore to $\mathrm{pH} \sim 2$ 167 with conc. Aristar Ultra HCl. Supporting oceanographic parameters were made 168 shipboard and are supplied by the Ocean Data Facility (Jenkins et al., 2015). 


\subsubsection{U.K. GEOTRACES GA10 D357 cruise}

171

172 Seawater samples were collected from Station $3\left(13.39^{\circ} \mathrm{S} 36.46^{\circ} \mathrm{W} ; 13\right.$ point profile,

$1732-4724 \mathrm{~m}$ ) on October $23^{\text {rd }} 2010$ as part of the GA10 D357 cruise on board the RRS

174 Discovery. Clean seawater samples were collected broadly as described by Wyatt et

175 al. (2014); briefly, seawater was collected into twenty four $10 \mathrm{~L}$ clean Teflon-coated

176 OTE samplers on a Titanium CTD frame on a plasma (polyethylene) rope. The OTE

177 bottles were transferred to a clean container, and water samples were filtered using

178 Millipore $25 \mathrm{~mm} 0.4 \mu \mathrm{m}$ polyethersulfone (PES) filters (>75 m depth) or $0.2 \mu \mathrm{m}$

179 AcroPak Supor Pall PES capsules ( $<75 \mathrm{~m}$ depth or fish samples). Filtered seawater

180 was collected into acid-cleaned and seawater-rinsed 1 L Nalgene LDPE bottles.

181 Seawater samples were acidified back on shore to $\mathrm{pH} \sim 2$ with conc. Aristar Ultra $\mathrm{HCl}$.

182 Salinity, temperature and oxygen were measured shipboard using standard methods as

183 described by Wyatt et al. (2014).

184

185

\subsubsection{French GIPY4 cruise}

186

187

188

189

190

191

192

193

194

195

196

197

198

199

200 Stable $\mathrm{Fe}$ isotope ratios $\left(\delta^{56} \mathrm{Fe}\right)$ are expressed for all laboratories in this paper in

201 standard delta notation, relative to IRMM-014:

Seawater samples were collected from Super-Station 1 (St. 18) $\left(13.12^{\circ} \mathrm{S} 36.51^{\circ} \mathrm{W}\right.$; 9 point profile, 31-4068 m) on February $20^{\text {th }} 2008$ as part of the GIPY4 MD166 Bonus Good Hope cruise on board the RV Marion Dufresne. Clean seawater samples were collected and filtered as described previously (Abadie et al. in review, Lacan et al. 2008, Lacan et al., 2010); briefly, 10 L seawater samples were collected into acidcleaned 12 L Go-Flo bottles mounted on a Kevlar wire. Go-Flo bottles were brought inside a clean container and seawater was filtered using Savillex PFA Teflon filtration units with $0.45 \mu \mathrm{m} 90 \mathrm{~mm}$ nucleopore membranes into $10 \mathrm{~L}$ flexible LDPE containers with PP closure, within a few hours of collection. Samples were acidified onboard with $1.7 \mathrm{~mL}$ per $\mathrm{L}$ of $9 \mathrm{M}$ twice-distilled $\mathrm{HCl}$.

\subsection{Analytical Methods}

202 


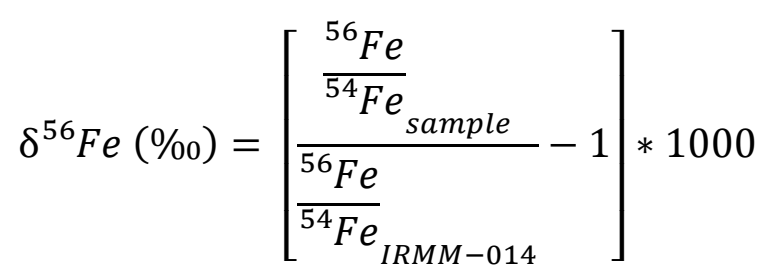

\subsubsection{IC1 Intercomparison Exercise}

206 Analytical methods for the four laboratories taking part in the IC-1 exercises were 207 described in full by Boyle et al. (2012) and by the respective labs (John and Adkins, 208 2012; Lacan et al., 2010, 2008; Rouxel and Auro, 2010), with subsequent analysis by 209 USC described below. For reference, three laboratories (WHOI, Caltech, LEGOS) used extraction of Fe from seawater with Qiagen NTA-Superflow resin, whilst one

211 laboratory used extraction using purified ammonium pyrrolidinedithiocarbamate and 212 sodium diethyldithiocarbamate and chloroform (ANU). All laboratories performed 213 analysis by Thermo Neptune MC-ICPMS, either with Ni and standard-sample 214 bracketing (WHOI, Caltech, ANU) or ${ }^{57} \mathrm{Fe}-{ }^{58} \mathrm{Fe}$ double spike technique (LEGOS) for 215 instrumental mass-bias correction. Uncertainty on $\delta^{56} \mathrm{Fe}$ is expressed as $2 \mathrm{SE}$ error for 216 ANU, and WHOI (Boyle et al. 2012), as $2 \sigma$ external error for Caltech (John and 217 Adkins., 2012) and as the 2SD on mean $\delta^{56}$ Fe for LEGOS (see Suppl. Data).

221 Samples were processed and analyzed at USC for Fe concentration and $\delta^{56} \mathrm{Fe}$ analysis 222 following several months of storage at $\mathrm{pH}$ 2, following already published methods, 223 with extraction by Nobias PA-1, purification by AGMP-1 resin and analysis by 224 Thermo Neptune MC-ICPMS with mass bias correction by ${ }^{57} \mathrm{Fe}-{ }^{58} \mathrm{Fe}$ double spike technique (Conway et al., 2013; Conway and John 2014a) in 'high' resolution (HR) mode to resolve polyatomic interferences such as $\mathrm{ArN}^{+}$and $\mathrm{ArO}^{+} .{ }^{54} \mathrm{Cr}$ and ${ }^{58} \mathrm{Ni}$ isobaric interferences on ${ }^{54} \mathrm{Fe}$ and ${ }^{58} \mathrm{Fe}$ were corrected for using the measured abundances of ${ }^{53} \mathrm{Cr}$ and ${ }^{60} \mathrm{Ni}$. A background correction was applied to each sample using the blank $0.1 \mathrm{M} \mathrm{HNO}_{3}$ acid, with this blank acid measured twice for every 230 group of $4-6$ samples. $\delta^{56} \mathrm{Fe}$ were calculated relative to an IRMM-double spike 231 mixture, which was concentration and matrix matched to the samples, and run twice 232 with each group of 4-6 samples. Seawater samples were spiked in a 1:2 sample:spike 
ratio, purified from $1 \mathrm{~L}$ and measured twice by MC-ICPMS with a mean value

234 calculated.

236 Following Conway et al. (2013), uncertainty on mean $\delta^{56} \mathrm{Fe}$ in figures and Suppl.

237 Data is expressed as $2 \sigma$ internal error, calculated from replicates and bracketing 238 standards, based on the previous observation that uncertainty with this technique is 239 dominated by internal error (John, 2012). For this study, $2 \sigma$ internal analytical error 240 varied from 0.04 to $0.18 \%$, largely dependent on sample Fe concentration. As an 241 indication of external precision for the method we also calculated the $2 \mathrm{SD}(0.05 \%)$ of 242 the offset of duplicate analyses from the mean of 60 South Atlantic GA10 seawater 243 samples $\left(0.1-1.8 \mathrm{nmol} \mathrm{kg}^{-1}\right)$, with duplicates measured in different analytical sessions 244 (following Steele et al., 2011). This calculated external precision is similar to or 245 smaller than internal error for most samples, suggesting that for these samples internal 246 error is a good representation of overall uncertainty.

248 Fe concentration measurements were made via isotope-dilution, with a procedural 249 blank of $0.005 \mathrm{nmol} \mathrm{kg}^{-1}$, with $2 \%$ uncertainty applied for weighing and pipetting 250 errors (Conway et al., 2013). We have previously shown strong agreement with other 251 laboratories for SAFE standards and profile concentration data produced with this 252 method (Conway et al., 2013; Middag et al., 2015). For some IC1 samples multiple 253 subsamples were purified separately and then each measured twice by MC-ICPMS; 254 here, a mean $\delta^{56} \mathrm{Fe}$ is used in figures.

\subsubsection{GIPY4 (LEGOS)}

258 Samples were processed and analysed at LEGOS for $\delta^{56} \mathrm{Fe}$ following previously 259 described methods (Lacan et al., 2008, 2010). Briefly, Fe was pre-concentrated from 2604 to $10 \mathrm{~L}$ of seawater using an NTA resin column and then purified with AG 1-x4 261 anionic exchange resin, before redissolution in $\sim 0.7 \mathrm{~mL} 0.3 \mathrm{M} \mathrm{HNO}_{3}$ for analysis by 262 MC-ICPMS using a Neptune (Thermo Scientific) coupled with a CETAC Aridus II 263 desolvation system. Instrumental mass bias and potential procedural fractionation was 264 corrected for using the double-spike technique, also following the iterative method of 265 Siebert et al. (2001). A ${ }^{57} \mathrm{Fe}-{ }^{58} \mathrm{Fe}$ double spike with a composition of $0.1 \%{ }^{54} \mathrm{Fe}$, $2662.94 \%{ }^{56} \mathrm{Fe}, 54.90 \%{ }^{57} \mathrm{Fe}$ and $42.06 \%{ }^{58} \mathrm{Fe}$ was added to samples in a 1:1 natural:spike 
ratio at least 12 hours prior to pre-concentration. Samples were analyzed in medium resolution mode (MR) to resolve polyatomic interferences, using the older Thermo MR slits $(30 \mu \mathrm{m})$, which correspond more closely to the newer HR slits $(18-25 \mu \mathrm{m})$. Isobaric interferences on ${ }^{54} \mathrm{Fe}$ and ${ }^{58} \mathrm{Fe}$ were corrected for using the measured abundances of ${ }^{53} \mathrm{Cr}$ and ${ }^{60} \mathrm{Ni}$.

As described by Lacan et al. (2010), each analytical session began with analysis of the in-house ETH Zürich hematite standard relative to IRMM-014 (both mixed with the double-spike), and then the hematite standard was analysed after every two samples as a check on accuracy and precision of the instrument. Each sample was bracketed by the blank acid, with 25 cycles of $8.4 \mathrm{~s}$ for samples and standards and 10 cycles of $8.4 \mathrm{~s}$ for blanks. This method has been shown to give excellent precision and accuracy over the full range of expected Fe concentrations in seawater $\left(0.05-1 \mathrm{nmol} \mathrm{kg}^{-1}\right)$ in volumes of 2-20 L, with full details described previously (Lacan et al, 2010). Final values are either means calculated from multiple Neptune analysis of a single $10 \mathrm{~L}$ sample, calculated from separate extractions of $5 \mathrm{~L}$ aliquots, or a combination of the two. $2 \sigma$ uncertainty on measurements is expressed as the long term reproducibility of the ETH Zürich standard (0.07\%o), as the repeatability from seawater samples yielded better results ( $2 \sigma$ from 0.01 to $0.05 \%$ ). Fe concentration measurements were made by isotope dilution, with a procedural blank corresponding to $0.002 \mathrm{nmol} \mathrm{kg}{ }^{-1}$ and uncertainty is expressed as 2SD of replicate analyses (Lacan et al., 2010).

\section{Results and Discussion}

The $\delta^{56} \mathrm{Fe}$ and $\mathrm{Fe}$ data discussed in this study are reproduced from other interpretive studies (Abadie et al., in review; Boyle et al., 2012; Conway and John, 2014a; John and Adkins, 2012; Lacan et al., 2008), with the exception of GA10 results, which are presented here for the first time. All data shown in figures are available as Suppl.

\subsection{GA03 (2011) and IC1 at Bermuda (2008)}

299 The water column profiles of $\mathrm{Fe}$ and $\delta^{56} \mathrm{Fe}$ for the BATS station from the IC1 and 300 GA03 cruises are shown in Fig $2 \mathrm{~b}$, with the $\delta^{56} \mathrm{Fe}$ values for the IC1 intercomparison 
301 depths shown in Fig. 2c-d. Good agreement within error was previously observed 302 between the labs taking part in the IC1 cruise in these samples, for the GSI surface (7 $303 \mathrm{~m}$; Fig. 2c) and GDI deep tanks (2000 m; Fig. 2d), with $\delta^{56} \mathrm{Fe}$ ranging from $304+0.24 \pm 0.10 \%$ o to $+0.41 \pm 0.04 \%$ for the surface tank and $+0.42 \pm 0.11 \%$ o to $305+0.52 \pm 0.07 \%$ o for the deep tank (Boyle et al., 2012, see Suppl. Data), with all labs 306 reporting data within 2SD of the mean of the five labs (GSI $+0.34 \pm 0.13 \%$ and GSD $307+0.48 \pm 0.10 \%$; $2 \mathrm{SD})$, demonstrating the ability of the individual labs to accurately 308 measure $\delta^{56} \mathrm{Fe}$ at dissolved $\mathrm{Fe}$ concentrations of 0.4 and $0.8 \mathrm{nmol} \mathrm{kg}^{-1}$.

310 For comparison of the IC1 and GA03 cruise, although samples were not taken at 311 exactly the same depth, we can compare samples of similar depth (Fig 2c-d). At the 312 surface, the GA03 towed fish sample $(\sim 2 \mathrm{~m})$ is within $2 \mathrm{SD}$ of the mean $\delta^{56} \mathrm{Fe}$ of the 313 GSI tank $(+0.23 \pm 0.07 \%$ and $+0.34 \pm 0.13 \%$; Fig. $2 \mathrm{c})$, and Fe concentrations show 314 similar good agreement (0.46 vs. $\left.0.41-0.45 \mathrm{nmol} \mathrm{kg}^{-1}\right)$. For the deep ocean, the GA03 315 samples collected at 1951 and $2101 \mathrm{~m}$ are also both within error of 2SD of the mean $316 \delta^{56} \mathrm{Fe}$ of the GDI tank $(+0.35 \pm 0.06 \%$ o $+0.43 \pm 0.07 \%$ and $+0.48 \pm 0.10 \%$; Fig. $2 \mathrm{~d})$, and 317 the $\delta^{56} \mathrm{Fe}$ of the GA03 sample at $2101 \mathrm{~m}$ is identical within error to the GSD Tank 318 mean $\delta^{56} \mathrm{Fe}$. Fe concentrations measured for this depth interval on the GA03 cruise 319 (0.61-0.65 nmol kg-1) were slightly lower than those for the GSD tank (0.74-0.84 $320 \mathrm{nmol} \mathrm{kg}{ }^{-1}$ ). Very similar temperature, oxygen and salinity profiles are also observed 321 between the cruises, suggesting consistent water mass structure (Fig. 2b); despite this, 322 given the dynamic nature of the marine Fe cycle, such consistency in $\delta^{56} \mathrm{Fe}$ at both 323 depths from the two cruises is remarkable. This is especially remarkable for the 324 surface ocean in different seasons (June and November) three years apart, when this 325 region of the ocean is prone to episodic atmospheric supply of Fe with both storm 326 activity and seasonality causing variability in the deposition of more-soluble 327 anthropogenic aerosol Fe vs. lower-solubility lithogenic aerosol Fe (e.g. Fishwick et 328 al., 2014; Sedwick et al., 2005; Sedwick et al., 2007; Wu and Boyle, 2002).

330 A lack of variability may in fact point to the stability of the Fe cycle in this region on 331 this timescale in terms of overall Fe sources and internal cycling processes such as 332 scavenging and biological uptake/release. Since anthropogenic and lithogenic aerosols 333 might be expected to alternately dominate deposition in winter and summer 334 respectively and have been suggested to have different $\delta^{56} \mathrm{Fe}$ signatures (Conway, T. 

it is perhaps surprising that there is such little variability in surface water dissolved

$337 \delta^{56} \mathrm{Fe}$. However, since the surface of neither profile is characterized by the very high

338 Fe concentrations that have been attributed to episodes of lithogenic dust deposition in 339 summer months (1-2 nmol kg-1; Sedwick et al., 2005), it may be that both profiles 340 reflect the longer-timescale combined effect of different Fe sources, equilibrium and 341 kinetic processes in concert with dust particles rather than the primary $\delta^{56} \mathrm{Fe}$ signature 342 of each dust source. We previously suggested that the heavy $\delta^{56} \mathrm{Fe}$ signature might 343 represent an equilibrium effect of dust particles being in contact with organic ligands 344 (Conway and John, 2014a), with the exchange/dissolution process in the presence of 345 ligands perhaps ultimately more important than the $\delta^{56} \mathrm{Fe}$ signature of either lithogenic 346 or anthropogenic aerosols. However, this remains a hypothesis and clearly more 347 process and experimental studies will be required to fully test this and to understand 348 what is ultimately responsible for heavier-than-crustal $\delta^{56} \mathrm{Fe}$ in surface Atlantic 349 waters. As such, we cannot presently assess on the basis of these datasets whether 350 episodic dust fluxes might cause dramatic effects on surface ocean dissolved $\delta^{56} \mathrm{Fe}$, 351 perturbing the profiles observed here, or whether the magnitude of local dust flux has 352 a negligible effect on $\delta^{56} \mathrm{Fe}$ because the surface ocean $\delta^{56} \mathrm{Fe}$ in this region is typically 353 dominated by an internal cycling process.

355 Higher resolution comparison of $\delta^{56} \mathrm{Fe}$ at BATS through the water column is also 356 possible because of the measurement of a 10 point $\delta^{56} \mathrm{Fe}$ profile on IC1 samples by 357 Caltech (John and Adkins, 2012; Boyle et al., 2012), and a 34 point profile for $\delta^{56} \mathrm{Fe}$ 358 measured on samples from the GA03 cruise (Conway and John, 2014a). A general 359 homogeneity of $\delta^{56} \mathrm{Fe}$ through the full water column $(+0.32 \%$ o to $+0.55 \%$ o with one 360 exception; Fig, 2b) for the IC1 samples was previously commented upon by John and 361 Adkins (2012), who attributed heavy $\delta^{56} \mathrm{Fe}$ to dust and the homogeneity to buffering 362 of the dissolved phase by particles. They also attributed one exceptionally heavy $\delta^{56} \mathrm{Fe}$ 363 value $(+0.78 \pm 0.07 \%)$ at $2500 \mathrm{~m}$ to a hydrothermal source. However, further study 364 called into question whether the heavy $\delta^{56} \mathrm{Fe}$ value at $2500 \mathrm{~m}$ (bracketed point, Fig. 3652 b) was representative of the ocean. Whilst the heavy $\delta^{56} \mathrm{Fe}$ value reported by John 366 and Adkins (2012) was confirmed by analyses at USC, this sample had anomalously 367 low $\mathrm{Zn}$ and $\mathrm{Cd}$ concentrations, poor reproducibility of $\mathrm{Fe}$ concentration, and 368 unexpectedly light $\delta^{66} \mathrm{Zn}$ in this sample, compared to the typically homogenous deep 
369 ocean $\delta^{66} \mathrm{Zn}$ value (-0.1 vs. $+0.5 \%$; Conway and John, 2014b; Conway and John 370 2015a; Conway et al., 2013; Zhao et al., 2014), suggesting that it was not 371 representative of $2500 \mathrm{~m}$ seawater, but rather that the Go-Flo bottle probably tripped 372 at the wrong depth. Additional analysis of $\delta^{56} \mathrm{Fe}$ over for the whole IC1 profile from 373 the same sample bottles at USC showed good overall agreement, within $2 \sigma$ quoted 374 uncertainty for most depths (Fig. 2b; Conway et al., 2013a; 2013b, Suppl. 375 Information). However, it is worth noting that at $1500 \mathrm{~m}, \delta^{56} \mathrm{Fe}$ measurements from 376 USC and Caltech were slightly greater $(0.13 \%)$ than the combined $2 \sigma$ uncertainty $377(0.12 \%)$ apart, and that, while typically within $2 \sigma$ uncertainty, the USC $\delta^{56} \mathrm{Fe}$ dataset 378 was generally heavier than Caltech by $\sim 0.1 \%$. These differences could point to a 379 slight underestimation of true analytical uncertainty by one or other of the methods, or 380 some effect of 5 years of sample storage.

382 A similar broad homogeneity in $\delta^{56} \mathrm{Fe}$ through the water column to that observed on 383 IC1 was reported for BATS from the GA03 cruise, with $\delta^{56} \mathrm{Fe}$ varying from +0.22 to $384+0.58 \%$, with the exception of one data point at $420 \mathrm{~m}(+0.7 \%$ o). Upon direct 385 comparison of $\delta^{56} \mathrm{Fe}$ data from the two cruises we observe very similar $\delta^{56} \mathrm{Fe}$ profile 386 shapes (Fig. 2b); in fact, with the exception of the IC1 samples at $250 \mathrm{~m}$ and $500 \mathrm{~m}$ 387 (where we have no direct comparison between cruises) and $2500 \mathrm{~m}$ (the flagged 388 sample), $\delta^{56} \mathrm{Fe}$ from the other 7 depths from the Caltech IC1 cruise agree well with 389 their depth counterparts from GA03, extending the observation of consistent $\delta^{56} \mathrm{Fe}$ in 390 GSI and GSD samples with GA03 to the full depth profile. Whilst most USC IC1 391 cruise data also agree well with GA03 within $2 \sigma$ uncertainty, the previously 392 mentioned $\delta^{56} \mathrm{Fe}$ data point at $1500 \mathrm{~m}$ appears to be slightly anomalously heavy 393 compared to the other two datasets, and the USC IC1 value at $4200 \mathrm{~m}(+0.45 \pm 0.06 \%)$ 394 is also slightly outside of $2 \sigma$ internal uncertainty of GA03 $(+0.29 \pm 0.06 \%)$, whilst 395 agreeing with Caltech $(+0.35 \pm 0.07 \%$ o). These differences could also point to small 396 variability between datasets, whether from natural variability, sampling contamination 397 or a slight underestimation of true analytical uncertainty. Nevertheless, the overall 398 agreement of the three datasets is strong, agreeing within $\sim 0.1 \%$, and so differing by 399 much smaller amounts than the range of variability observed elsewhere in the ocean 400 (e.g. Fig 2-4). 
402 The higher resolution of the GA03 profile compared to IC1 permits the observation of 403 systematic variability in the deep ocean, with depth intervals where $\delta^{56} \mathrm{Fe} \leq+0.3 \%$ 404 (800-1800 $\mathrm{m}$ and $>3600 \mathrm{~m})$ and $>0.3 \%$ between $1800-3600 \mathrm{~m}$, corresponding to the 405 influence of Upper Labrador Seawater and deep nepheloid layers respectively 406 (Jenkins et al., 2015; Ohnemus and Lam, 2015), and attributed to the influence of 407 non-reductive sedimentary Fe (Conway and John, 2014a). Whilst the presence of 408 similar $\delta^{56} \mathrm{Fe}$ structure can not be assessed for IC1 due to the depth resolution, the 409 consistency of the full water column profile between the cruises does suggest that the 410 broad external source addition and internal cycling processes that determine dissolved $411 \delta^{56} \mathrm{Fe}$ throughout the water column in this region are likely to be similar at both times.

412 In terms of dissolved Fe concentration, the profiles for both cruises are very similar 413 above $1500 \mathrm{~m}$ (Fig. 2a), including a surface enrichment ( 0.4-0.5 nmol kg${ }^{-1}$ ) and 414 pronounced dissolved Fe minimum at 120-140 $\mathrm{m}\left(0.1-0.2 \mathrm{nmol} \mathrm{kg}^{-1}\right)$ in both cruises. 415 Below $1500 \mathrm{~m}, \mathrm{Fe}$ concentrations were slightly higher on the IC1 cruise (0.1-0.2 nmol $416 \mathrm{~kg}^{-1}$ ) at the two comparable depths.

\subsection{GA03 (2010 and 2011) at Cape Verde}

The GA03 section was completed on two cruises in 2010 and 2011, with station 421 identification defined as USGT, then 10 or 11 for year, then station number (e.g. USGT10-12). The cruises overlapped with reoccupation of the Tenatso Time Series station $\left(17.40^{\circ} \mathrm{N} 24.50^{\circ} \mathrm{W}\right)$ near Cape Verde by the GA03 cruise in Oct. 2010 424 (USGT10-12) and Nov. 2011 (USGT11-24). Depth and density profiles of dissolved $\delta^{56} \mathrm{Fe}$ and $\mathrm{Fe}$ are shown for these two stations in Fig. 3b-c.

Both occupations were characterized by very similar temperature, salinity and oxygen vertical profiles on both density and depth scales, with oxygen slightly higher in 2010 (Fig. 3b-c). The vertical structure is strongly dominated by the Mauritanian Oxygen Minimum Zone (OMZ) present between $200-1000 \mathrm{~m}$, with dissolved oxygen as low

431 as $60 \mu \mathrm{mol} \mathrm{kg} \mathrm{kg}^{-1}$, as well as a very shallow mixed layer ( 40-50 m; Hatta et al., 2015).

432 The dissolved Fe concentration profiles for both stations reflect this vertical structure, 433 with both showing a surface enrichment of $0.3-0.4 \mathrm{nmol} \mathrm{kg}^{-1}$ in the mixed layer, 434 presumably from atmospheric dust, a dissolved Fe minimum of 0.1-0.2 nmol kg ${ }^{-1}$ just 435 below the mixed layer (associated with the fluorescence maximum; 60-70 m), 
436 elevated concentrations of $0.8-1.2 \mathrm{nmol} \mathrm{kg}^{-1}$ through the $\mathrm{OMZ}$ horizon, and $\mathrm{Fe}$ 437 concentrations declining to $0.6 \mathrm{nmol} \mathrm{kg}^{-1}$ in the deep ocean (Conway and John, 438 2014a; Fig. 3b). Although dissolved Fe profiles from both years show very similar 439 overall shapes, and strong consistency in waters $>1000 \mathrm{~m}$, there is some apparent 440 variability within surface waters and especially throughout the OMZ horizon (Fig. $4413 b$ ), a feature also reported by other investigators reporting dissolved $\mathrm{Fe}, \mathrm{Fe}$-binding 442 ligands, $\mathrm{Fe}$ size fractionation and other parameters such as $\mathrm{Pb}$ concentrations and $\mathrm{Cd}$ 443 isotopes on GA03 (Buck et al., 2015; Conway and John, 2014a; 2015b; Fitzsimmons et al., 2015; Hatta et al., 2015; Noble et al., 2015). Potential inter-annual variability is

$\delta^{56} \mathrm{Fe}$ measurements through the water column at this location show greater variability in a single profile than at the BATS station (Section 3.1), with both USGT10-12 and USGT11-24 spanning a range of $0.7 \%$ (between 0 and $+0.7 \%$ ). Similar to the consistency in dissolved $\mathrm{Fe}$ concentrations, the $\delta^{56} \mathrm{Fe}$ profiles for both years are broadly similar in shape, with heavy $\delta^{56} \mathrm{Fe}$ values in the mixed layer $(>+0.4 \%)$, a sub-surface minima ( $0 \%$ ), values of 0 to $+0.3 \%$ within the $\mathrm{OMZ}$ region, and values increasing from +0.2 to as high as +0.7 in deep water, as Fe concentrations decline (Fig. 3b). This structure was previously attributed to isotopically heavy Fe released from dust $(+0.7 \%)$ in the surface mixed layer and the deep ocean, mixing with a reductive sediment light $\mathrm{Fe}(<-1 \%)$ that is transported throughout the water column, (but mostly within OMZ waters) from reducing sediments on the Mauritanian margin

Samples were collected at the same depth on each cruise, allowing direct comparison 461 of $\delta^{56} \mathrm{Fe}$ values for each profile. For the surface dissolved $\mathrm{Fe}$ enrichment in the mixed 462 layer, $\delta^{56} \mathrm{Fe}$ were very similar between cruises $(2-50 \mathrm{~m} ;+0.52 \pm 0.09 \%$ and $463+0.41 \pm 0.09 \%$ in $2010,+0.60 \pm 0.09 \%$ o, $+0.60 \pm 0.09 \%$ o, and $+0.63 \pm 0.09 \%$ o in 2011 ; Fig. 464 3b). In density space, these surface values show poorer agreement (Fig. 3c), perhaps 465 due to changes in the relative importance of North Atlantic Central Water or Atlantic 466 Equatorial Water between the two years (Hatta et al, 2015; Jenkins et al., 2015). 467 However, if isotopically heavy values are the result from local surface dissolution of 468 sinking dust, then variability in vertical density may not be an appropriate parameter 469 for comparison. Below the mixed layer, from $70-240 \mathrm{~m}$ depth, the two profiles are 
470 equivalent within error for $\delta^{56} \mathrm{Fe}$, with $\delta^{56} \mathrm{Fe}$ values of $+0.2 \%$ associated with both the 471 subsurface dissolved Fe concentration minimum and fluorescent maximum, as well as 472 a $\delta^{56} \mathrm{Fe}$ minimum of $0.0 \%$ just below the Fe minimum, when Fe concentrations begin 473 to rise. While it is not yet clear what process causes this intriguing subsurface 474 structure, such as regeneration, uptake or scavenging, it is reproduced for both years 475 here, and was also observed associated with the Fe minimum in other nearby GA03 476 profiles (Conway and John, 2014a). Surface variability in the top $300 \mathrm{~m}$ may be 477 induced by not only changes in atmospheric dust deposition and biological processes, 478 but also in the relative importance of different surface water masses with different 479 characteristics, so it is notable that $\mathrm{Fe}$ and $\delta^{56} \mathrm{Fe}$ are so consistent at shallow depths.

481 Set against the broad similar $\delta^{56} \mathrm{Fe}$ profile shapes, there is poorer agreement between $482 \delta^{56} \mathrm{Fe}$ depth pairs throughout both the OMZ horizon and the deeper ocean $(>200 \mathrm{~m})$. 483 With the exception of $\delta^{56} \mathrm{Fe}$ data from $3198 \mathrm{~m}$, the $\delta^{56} \mathrm{Fe}$ profile from 2011 is notably 484 isotopically heavier than that of 2010 (by 0.03 to $0.3 \%$ ). While some of these 485 differences ( 8 of the 17 depths) are within combined $2 \sigma$ uncertainty $(\geq 0.10 \%$ ), some 486 are larger (Fig. 3b; Suppl. Data). Indeed, throughout the OMZ horizon ( 200-1000 m; 487 shown as a blue bar in Fig 3b), where most of the Fe concentration measurements are 488 different between the two cruises (by 0.1 to $0.2 \mathrm{nmol} \mathrm{kg}^{-1}$ ), four of the seven $\delta^{56} \mathrm{Fe}$ 489 data points are outside of error of each other. Deeper in the ocean (below $1000 \mathrm{~m}$ ), 490 while $\mathrm{Fe}$ concentrations show strong consistency, $\delta^{56} \mathrm{Fe}$ show more variability 491 between the cruises, identical within error between 1000 and 1300 m, 2000-2300 and $492>3000 \mathrm{~m}$, but differing between 1500-1750 and 2500-3000 m. Whilst Fe 493 concentrations are consistent for most of these depths (differing by $<0.02 \mathrm{nmol} \mathrm{kg}^{-1}$, 494 similar to expressed error of 0.01-0.02 $\mathrm{nmol} \mathrm{kg}^{-1}$ ), the largest differences in $\delta^{56} \mathrm{Fe}$ in 495 this interval $(0.19 \%$ and $0.26 \%$ at 1500 and $2748 \mathrm{~m}$ respectively) are found at depths 496 where Fe concentrations are subtly more different (0.06-0.1 nmol kg-1). Thus, while it 497 is possible that some of this variability in $\delta^{56} \mathrm{Fe}$ in the deep ocean represents 498 differences in background contamination or under-estimation of $\delta^{56} \mathrm{Fe}$ analytical 499 uncertainty, especially when it is not accompanied by changes in Fe concentration, it 500 is consistent with observed variability in other oceanographic parameters. Variability 501 in Fe cycling would also not be unexpected, given the dynamic oceanographic nature 502 of this region. Upwelling of nutrient and Fe rich deep water, high productivity in 503 surface waters, an OMZ at intermediate depths facilitating potential advection of shelf 
$504 \mathrm{Fe}$, and the presence of Antarctic water masses at intermediate depths could all lead to

505 variability in $\mathrm{Fe}$ cycling and hence $\delta^{56} \mathrm{Fe}$ signatures.

507 Variability in $\delta^{56} \mathrm{Fe}$ and $\mathrm{Fe}$ in the deep ocean is also consistent with the idea that 508 dissolved $\mathrm{Fe}$ in this region is dominantly locally sourced from atmospheric dust or 509 reductive sediments that have very different $\delta^{56} \mathrm{Fe}$ signatures (Conway and John, 510 2014a); thus, small changes in either sediment or dust supply could dramatically 511 influence $\delta^{56} \mathrm{Fe}$, while having only a small effect on Fe concentrations. A shelf source 512 of Fe might be expected to have a waning influence with distance from Africa, as 513 well as varying with strength over time, while dust supply would also be episodic and 514 seasonal. If we examine data from stations USGT10-12 and 11-24 in the context of 515 nearby stations (USGT10-11 and USGT11-24; Fig. 3a; Suppl. Fig. 1), it can be 516 observed that USGT11-22, a 2011 station further from Africa (Fig. 3a), is 517 characterized by much lower Fe concentrations throughout the water column as well 518 as generally heavier $\delta^{56} \mathrm{Fe}$, while USGT10-11, a 2010 station nearer to Africa, is 519 practically identically to USGT10-12 for $\delta^{56} \mathrm{Fe}$ below $500 \mathrm{~m}$. Given that USGT11-24 520 looks more similar to USGT11-22 below $800 \mathrm{~m}$ within the depth intervals at which 521 USGT10-12 and USGT11-24 disagree (lower Fe concentrations and higher $\delta^{56} \mathrm{Fe}$ ), it 522 is possible to interpret the full water-column variability as being driven by a changing 523 component of isotopically light $\mathrm{Fe}$ from reductive sediments that is slightly greater in 5242011 than 2010. At shallower depths (286-451 m), USGT11-24 is characterized by 525 higher Fe concentrations and heavier $\delta^{56} \mathrm{Fe}$ than both USGT10-11 and USGT10-12, as 526 well as slightly lower oxygen (Suppl. Fig. 1; Fig 3b; Hatta et al., 2015); thus, this 527 difference could not be explained by an increased source of light Fe in 2011, but 528 perhaps rather by a greater dissolution of atmospheric dust or regeneration of $\mathrm{Fe}$ 529 within the OMZ. 3.3 GIPY4 (2008) and GA10 (2010)

533 Water-column profiles of dissolved $\delta^{56} \mathrm{Fe}$ and Fe for and GIPY4 Super-Station S1 534 (2008) and GA10 D357 Station 3 (2010) from the Cape Basin in the Eastern South 535 Atlantic are shown, together with supporting oceanographic parameters, plotted 536 against both depth and density in Fig. 4. Below 700 m, similar temperature, oxygen 537 and salinity profiles are observed for both cruises, whilst in surface waters the GIPY4 
cruise was characterized by much warmer, fresher, less dense water than GA10 (Fig. 4b-c). This difference can be most clearly observed in density space for $\sigma_{\theta}<26.75 \mathrm{~kg}$ $\mathrm{m}^{-3}$ (Fig. 4c), indicative of different surface waters dominating the upper water column $(<700 \mathrm{~m})$ during the two cruises. This difference could be due to movement in the position of the South Subtropical Convergence, which is located near this station (Fig. 1 of Browning et al., 2014), and/or the variable influence of the Agulhas current, which variably transports warm salty surface water from the Indian Ocean to the South Atlantic within mesoscale structures (Lutjeharms, 2006). Indian ocean water is transported into the Atlantic within the Agulhas retroflection, typically in the form of large anticyclonic eddies ('Agulhas rings'; Lutjeharms, 2006). Such rings, characterized both on the GA10 and GIPY4 cruises by elevated temperature, salinity and nutrients ( $\mathrm{S}>35$; T $15-23^{\circ} \mathrm{C}$; Arhan et al., 2011; Wyatt et al., 2014), can have an important effect on both biogeochemical cycling in surface waters (Viller et al., 2015); indeed, it was recently shown that Agulhas rings transport an Indian Ocean $\mathrm{Pb}$ isotope signature to the North Atlantic (Paul et al., 2015), suggesting that they could also play a role in influencing the surface ocean cycling of $\mathrm{Fe}$ and other trace metals.

The difference in surface water characteristics is also reflected in the Fe concentration profiles, which show broad similarity for both cruises below $400 \mathrm{~m}$, but disagreement in surface waters $<100 \mathrm{~m}$ where dissolved Fe was $0.2-0.3 \mathrm{nmol} \mathrm{kg}^{-1}$ in 2008 and $<0.09 \mathrm{nmol} \mathrm{kg}^{-1}$ in 2010, perhaps due to the transport of higher Fe concentrations within warmer saltier Indian Ocean water compared to colder more-Fe depleted Atlantic waters. As might be expected, with the surface variability in surface waters and $\mathrm{Fe}$ concentrations, $\delta^{56} \mathrm{Fe}$ between the cruises show differences between the two cruises (Fig. 4b); $\delta^{56} \mathrm{Fe}$ from GIPY4 are rather homogenous over the top $400 \mathrm{~m}$, and close to crustal (+0.09\%; Beard et al., 2003; Lacan et al., 2008), varying only between $+0.04 \pm 0.07 \%$ and $+0.21 \pm 0.07 \%$. In contrast, although subject to larger uncertainties at low surface Fe concentrations, $\delta^{56} \mathrm{Fe}$ from GA10 show more variability in the top $500 \mathrm{~m}$, ranging from $-0.22 \pm 0.10 \%$ to $+0.51 \pm 0.22 \%$. When compared in density space (Fig. 4c), it becomes clear that much of the GIPY4 data are from lower density waters; this, together with the documented agreement of data from the two labs at BATS (Section 3.1) and in the deep ocean at this location (see below), suggests that this variability in $\delta^{56} \mathrm{Fe}$ may be natural rather than analytical and could perhaps also be attributed to the greater influence of Indian Ocean water in 2008. 
572 Although to date no $\delta^{56} \mathrm{Fe}$ data has been reported from the Indian Ocean, the near573 crustal homogenous $\delta^{56} \mathrm{Fe}$ in Indian Ocean water above $400 \mathrm{~m}$ could reflect non574 reductive release of Fe from sediments as suggested in the Equatorial Pacific and 575 North Atlantic Oceans (Radic et al., 2011; Conway and John, 2014a, Labutut et al, 576 2014) and observed in situ within sediment pore waters (Homoky et al., 2013).

578 In terms of the ocean below $\sim 500 \mathrm{~m}$, the South Atlantic at this location is dominated 579 by the lateral South-North or North-South movement of Southern- and Northern580 sourced water masses, especially for nutrients and trace metals such as $\mathrm{Zn}$ (Wyatt et 581 al., 2014). The depth intervals of these water masses, specifically Antarctic 582 Intermediate Water (AAIW), Upper Circumpolar Deep Water (UCDW), North 583 Atlantic Deep Water (NADW), and Antarctic Bottom Water (AABW), are shown in 584 Fig. 4b-c, and are defined following Wyatt et al. (2014), based either on salinity, with 585 NADW $>34.75(\sim 1700-4000 \mathrm{~m})$ and AAIW $<34.4$. For $\delta^{56} \mathrm{Fe}$ below $700 \mathrm{~m}$, the two $586 \delta^{56} \mathrm{Fe}$ profiles are identical within $2 \sigma$ uncertainty (Fig. 4b). Above this, between $500-$ $587700 \mathrm{~m}$, although there are no direct comparable samples, there appears to be a 588 disagreement in $\delta^{56} \mathrm{Fe}$. However, for comparison purposes it is important to note that 589 the salinity minimum corresponding to AAW was from $~ 500-950 \mathrm{~m}$ for GA10 (as 590 shown in Fig. 4b), but deeper (750-950 m) for GIPY4, suggesting that the isotopically 591 light $\delta^{56} \mathrm{Fe}$ of $-0.18 \pm 0.09 \%$ at $594 \mathrm{~m}$ from GA10 is in fact most comparable to the $5920.17 \pm 0.07 \%$ at $763 \mathrm{~m}$ from GIPY4; this can be seen more clearly in density space 593 (Fig 4c). With this adjustment in mind, $\delta^{56} \mathrm{Fe}$ can be considered identical within 594 uncertainty for both cruises over the entire water column below $500 \mathrm{~m}$. This 595 remarkable consistency in water-column $\delta^{56} \mathrm{Fe}$, in contrast to surface waters at this 596 location, highlights the quality of data being produced by both laboratories, as well as 597 again pointing to the stability of Fe sources and cycling in the ocean at this location 598 on this timescale, similar to that suggested at Bermuda.

600 Little temporal variability on this timescale suggests that the deep water masses at this 601 location may have relatively stable transported $\delta^{56} \mathrm{Fe}$ signatures, similar to that 602 observed in the Western North Atlantic (Section 3.1). Such signatures can be 603 observed when water mass horizons are shown on the $\delta^{56} \mathrm{Fe}$ profile (Fig. 4b), with 604 AABW $(+0.21 \pm 0.07 \%$, and $+0.21 \pm 0.09 \%$ ) slightly isotopically heavier than crustal, 605 NADW $(+0.29 \pm 0.06 \%, \quad+0.33 \pm 0.07$, and $+0.27+0.07 \%)$ distinctly isotopically 
606 heavier than crustal, while UCDW $(-0.12 \pm 0.07 \%$ and $-0.09 \pm 0.15 \%$ o) and AAIW (-

$6070.17 \pm 0.07 \%$ and $-0.18 \pm 0.09 \%$ ) are both isotopically light. One additional GA10 608 sample from $2000 \mathrm{~m}$, from shallower depths of NADW, was slightly lighter $609(+0.17 \pm 0.08 \%)$, perhaps reflecting mixing with the above-lying isotopically lighter

610 UCDW. While it is not clear what might cause these differences in water mass $\delta^{56} \mathrm{Fe}$ 611 signatures, it could point to $\delta^{56} \mathrm{Fe}$ retained from different dominant $\mathrm{Fe}$ sources (e.g. 612 reductive versus non-reductive sediment dissolution), or to fractionation processes 613 during formation or transport of these water masses. These ideas are explored in 614 greater detail in the context of the full GIPY4 section in Abadie et al. (in review).

\section{Conclusions}

618 We have presented the first oceanic comparison of dissolved $\delta^{56} \mathrm{Fe}$ depth profiles 619 from three locations in the Atlantic Ocean, including the first full profile inter-lab comparison, and comparison with a previous inter-calibration exercise. We find that:

621 (1) There is strong agreement between data and profiles produced by the two laboratories compared in this study, and the five laboratories compared in the previous exercise, which allows the combination and interpretation of $\delta^{56} \mathrm{Fe}$ datasets from different laboratories. Where discrepancies exist between laboratories, they are typically on the order of $0.1 \%$, which is occasionally greater than stated analytical uncertainty, but much less than the overall variability in $\delta^{56} \mathrm{Fe}$ observed within the global ocean. While some of this discrepancy may be due to true analytical error or sample storage/handling, our data suggest that variability between cruises may also be driven by true natural variability in $\delta^{56} \mathrm{Fe}$. Thus, repeat occupation of oceanic stations

630 by different GEOTRACES cruises and $\delta^{56} \mathrm{Fe}$ analysis by different laboratories is 631 essential for continued evaluation and comparison of analytical methods, but also 632 permits evaluation of temporal variability in oceanic Fe cycling. (2) At all three 633 locations compared in this study, there was remarkable agreement in the overall shape 634 of $\delta^{56} \mathrm{Fe}$ profiles on a 1-3 year timescale, including almost complete agreement over 635 the full water column at Bermuda in the Western North Atlantic and for the water 636 column below $500 \mathrm{~m}$ in the South Atlantic. (3) Set against this overall homogeneity in $637 \delta^{56} \mathrm{Fe}$, we observe apparent natural variability in $\delta^{56} \mathrm{Fe}$ in shallow waters in the South 638 Atlantic, and throughout the water column in the Eastern subtropical North Atlantic, 639 close to North Africa. Overall, where $\delta^{56} \mathrm{Fe}$ invariance is observed, we suggest that 
640 the internal cycling and sources of $\delta^{56} \mathrm{Fe}$ is stable on these timescales, in regions of 641 the oceans dominated by stable water-masses or single Fe sources (e.g. atmospheric 642 dust). However, $\delta^{56} \mathrm{Fe}$ may be more dynamic in surface waters with variable currents, 643 upwelling/regeneration or low-oxygen waters, which may either facilitate the supply 644 of $\mathrm{Fe}$ from different sources with different $\delta^{56} \mathrm{Fe}$ signatures or changes in the internal 645 cycling of Fe. Taken together, this work lends weight to the use of $\delta^{56} \mathrm{Fe}$ as a tracer to 646 increase our understanding of the variability in supply from different Fe sources and 647 transport of Fe through the oceans, or in internal Fe cycling.

\section{Acknowledgements}

651 We thank the Captains, crew, chief scientists and sampling teams for water collection 652 on the cruises described here, as well as the GEOTRACES scientific steering 653 committee and all those involved in coordinating the GEOTRACES program and 654 inter-comparison efforts. We especially thank M. Lohan on the GA10 cruise for water 655 collection (funded by NERC grant NE/H004475/1), and J. Wu, R. Middag, K. 656 Bruland, C. Schlosser and G. Sarthou for providing concentration data which was 657 helpful in planning double-spike additions on GA03, GA10 and GIPY4. We also 658 thank A. Rosenberg for technical assistance at the University of South Carolina, C. 659 Pradoux, A. Radic and J. Chmeleff for help in the lab and with ICPMS at LEGOS, M. 660 Boyé, S. Speich and their collaborators for providing the nutrient and physical 661 parameters for GIPY4, and G. de Souza for useful discussions. We thank two 662 anonymous reviewers for their helpful comments which allowed us to improve this 663 manuscript. Ocean data facility provided supporting nutrient and oceanographic 664 parameters for GA03. This study was funded by National Science Foundation grant 665 OCE-1131387 to S. John, ETH Zürich, the Swiss National Science Foundation, and 666 the French National Center for Scientific Research (CNRS). 
670 described in this study. Cruises included in the GEOTRACES Intermediate data 671 product 2014 are shown for reference, based on eGEOTRACES graphics (Mawji et 672 al., 2015; Schlitzer, 2015). The three locations sampled in this study are shown as 673 black dots.

Figure 2. Comparison of $\delta^{56} \mathrm{Fe}$ and Fe data from Bermuda Atlantic Time Series (BATS) in the subtropical North West Atlantic $\left(31.75^{\circ} \mathrm{N} 64.17^{\circ} \mathrm{W}\right)$ from the U.S. GEOTRACES IC1 (June 2008) and GA03 cruises (Nov. 2011). a) Regional location map showing BATS and GA03 stations sampled for Fe isotope ratios. b) dissolved $\mathrm{Fe}$ concentration (nmol $\mathrm{kg}^{-1}$ ) and dissolved $\delta^{56} \mathrm{Fe}$ (relative to IRRM-014) profiles shown with other oceanographic parameters. c) dissolved $\delta^{56} \mathrm{Fe}$ from the IC1 surface tank and from GA03 towed-fish sample. d) dissolved $\delta^{56} \mathrm{Fe}$ from the IC1 2000 me depths deep tank and from GA03 rosette samples from similar depths. The dashed lines and grey shaded region in b) and c) represent the mean and $2 \mathrm{SD} \delta^{56} \mathrm{Fe}$ respectively of the five labs that have published measurements for the GSI and GDI tanks. Data are reproduced from Boyle et al. (2012); Conway and John (2014a); Conway et al. (2013a; 2013b); John and Adkins (2012). Error bars for ANU and WHOI are from Boyle et al. (2012), error bars for LEGOS represent 2SD on $\delta^{56} \mathrm{Fe}$ (see Suppl. Data), error bars for Caltech are from John and Adkins (2012) and error bars for USC are from Conway et al. (2013) and Conway and John (2014a). For

690 GA03, temperature and salinity are from the GEOTRACES rosette and dissolved 691 oxygen is from the ODF rosette. and USGT11-24 $\left(17.4^{\circ} \mathrm{N} 24.5^{\circ} \mathrm{W}\right)$ from the Tenatso Time Series station in the North East Atlantic. a) Regional location map showing GA03 stations sampled for

696 Fe isotope ratios. Dissolved Fe concentration $\left(\mathrm{nmol} \mathrm{kg}^{-1}\right.$ ), dissolved $\delta^{56} \mathrm{Fe}$ (relative to 697 IRRM-014) and oceanographic parameters shown against depth (b) or $\sigma_{\theta}$ density (c). 698 Data and $2 \sigma$ error bars are from Conway and John (2014a). Temperature and salinity 699 are from the GEOTRACES rosette and dissolved oxygen is from the ODF rosette. 
700 The shaded below denotes the influence of the Mauritanian Oxygen Minimum Zone

701 (OMZ; dissolved oxygen $<120 \mu \mathrm{mol} \mathrm{kg}{ }^{-1}$ ).

702

703 Figure 4. Comparison of $\delta^{56} \mathbf{F e}$ and Fe profiles from Superstation 3 of GA10 704 D357 cruise and Super-Station 1 (station 18) of GIPY4 cruise in the South East

705 Atlantic. a) Regional location map showing GIPY4 and GA10 stations sampled for 706 Fe isotope ratios. Dissolved Fe concentration $\left(\mathrm{nmol} \mathrm{kg}^{-1}\right)$ and dissolved $\delta^{56} \mathrm{Fe}$ (relative 707 to IRRM-014) shown against depth (b) or $\sigma_{\theta}$ density (c). Data are from Abadie et al. 708 (in review), Lacan et al. (2008), or are previously unpublished. Error bars are $2 \sigma$ as 709 described in the text. GA10 temperature and salinity are from the titanium rosette and 710 oxygen from the stainless steel rosette, corrected to match bottle measurements. GIPY 711 temperature, salinity and oxygen data are from the Niskin Rosette. The horizontal 712 shaded bars represent the presence of different water masses based on salinity (see 713 text; Antarctic Intermediate Water, AAIW; Upper Circumpolar Deep Water, UCDW; 714 North Atlantic Deep Water, NADW; Antarctic Bottom Water, AABW). N.B. The 715 position of AAIW in depth space is based on GA10 and was deeper for GIPY4. 


\section{References}

Abadie, C. Lacan, F., Radic, A., Pradoux, C., Poitrasson, F. In review. Iron isotopes reveal distinct dissolved iron sources and pathways in the intermediate versus deep Southern Ocean. Proc. Natl Acad. Sci. USA.

Anderson, R.F., Henderson, G.M., 2005. GEOTRACES A global study of the marine biogeochemical cycles of trace elements and their isotopes. Oceanography 18, 76-79. doi:10.5670/oceanog.2005.31

Arhan, M., Speich, S., Messager, C., Dencausse, G. Fine, R., and Boye, M., 2011. Anticyclonic and cyclonic eddies of subtropical origin in the subantartic zone south of Africa. J. Geophys. Res. 116, C11, doi:10.1029/2011JC007140

Beard, B.L., Johnson, C.M., Von Damm, K.L., Poulson, R.L., 2003. Iron isotope constraints on Fe cycling and mass balance in oxygenated Earth oceans. Geology 31, 629-632. doi:10.1130/0091-7613(2003)031<0629:IICOFC>2.0.CO;2

Boyle, E.A., John, S.G., Abouchami, W., Adkins, J.F., Echegoyen-Sanz, Y., Ellwood, M.J., Flegal, A. R., Fornace, K., Gallon, C., Galer, S., Gault-Ringold, M., Lacan, F., Radic, A., Rehkämper, M., Rouxel, O., Sohrin, Y., Stirling, C., Thompson, C., Vance, D., Xue, Z., and Yhao, Y. 2012. GEOTRACES IC1 (BATS) contamination-prone trace element isotopes $\mathrm{Cd}, \mathrm{Fe}, \mathrm{Pb}, \mathrm{Zn}, \mathrm{Cu}$, and $\mathrm{Mo}$ intercalibration. Limnol. Oceanogr. Methods 10, 653-665. doi:10.4319/lom.2012.10.653

Browning, T.J., Bouman, H.A., Moore, C.M., Schlosser, C., Tarran, G.A., Woodward, E.M.S., Henderson, G.M., 2014. Nutrient regimes control phytoplankton ecophysiology in the South Atlantic. Biogeosciences 11, 463-479. doi:10.5194/bg-11-463-2014

Buck, K.N., Sohst, B., Sedwick, P.N., 2015. The organic complexation of dissolved iron along the U.S. GEOTRACES (GA03) North Atlantic Section. Deep Sea Res. Part II Top. Stud. Oceanogr. 116, 152-165. doi:10.1016/j.dsr2.2014.11.016

Chever, F., Rouxel, O.J., Croot, P.L., Ponzevera, E., Wuttig, K., Auro, M., 2015. Total dissolvable and dissolved iron isotopes in the water column of the Peru upwelling regime. Geochim. Cosmochim. Acta 162, 66-82. doi:10.1016/j.gca.2015.04.031

Conway, T.M., John, S.G., 2014a. Quantification of dissolved iron sources to the North Atlantic Ocean. Nature 511, 212-215. doi:10.1038/nature13482

Conway, T.M., John, S.G., 2014b. The biogeochemical cycling of zinc and zinc isotopes in the North Atlantic Ocean. Global Biogeochem. Cycles 28, 11111128. doi:10.1002/2014GB004862 
Conway, T.M., John, S.G., 2015a. The cycling of iron, zinc and cadmium in the North East Pacific Ocean - insights from stable isotopes. Geochim. Cosmochim. Acta. 164 (1), 262-283. doi:10.1016/j.gca.2015.05.023

Conway, T.M., John, S.G., 2015b. Biogeochemical cycling of cadmium isotopes along a high-resolution section through the North Atlantic Ocean. Geochim. Cosmochim. Acta. 148, 269-283. doi:10.1016/j.gca.2014.09.032

Conway, T.M., Rosenberg, A.D., Adkins, J.F., John, S.G., 2013a. A new method for precise determination of iron, zinc and cadmium stable isotope ratios in seawater by double-spike mass spectrometry. Anal. Chim. Acta 793, 44-52. doi:10.1016/j.aca.2013.07.025

Conway, T.M., Rosenberg, A.D., Adkins, J.F., John, S.G., 2013b. Corrigendum to "A new method for precise determination of iron, zinc and cadmium stable isotope ratios in seawater by double-spike mass spectrometry." [Anal. Chim. Acta 793, 44-52]. Anal. Chim. Acta 801, 97. doi:10.1016/j.aca.2013.09.010

Cutter, G., Andersson, P. Codispoti, L. Croot, P., François, R., Lohan, M. C. , Obata, H., Rutgers van der Loeff, M., 2010. Sampling and Sample-handling Protocols for GEOTRACES Cruises. Version 1.0, December 2010, http://www.geotraces.org/images/stories/documents/intercalibration/Cookbook_v 1_2010.pdf

Cutter, G.A., 2013. Intercalibration in chemical oceanography-Getting the right number. Limnol. Oceanogr. Methods 11, 418-424. doi:10.4319/lom.2013.11.418

Cutter, G.A., Bruland, K.W., 2012. Rapid and noncontaminating sampling system for trace elements in global ocean surveys. Limnol. Oceanogr. Methods, 10(6), 425436. doi:10.4319/lom.2012.10.425

Cutter, G., Andersson, P. Codispoti, L. Croot, P., François, R., Lohan, M. C. , Obata, H., Rutgers van der Loeff, M., 2014. Sampling and Sample-handling Protocols for GEOTRACES Cruises. Version 2.0, December 2014, http://www.geotraces.org/images/stories/documents/intercalibration/Cookbook.p df

de Jong, J., Schoemann, V., Tison, J.L., Becquevort, S., Masson, F., Lannuzel, D., Petit, J., Chou, L., Weiss, D., Mattielli, N., 2007. Precise measurement of Fe isotopes in marine samples by multi-collector inductively coupled plasma mass spectrometry (MC-ICP-MS). Anal. Chim. Acta 589, 105-119. doi: 10.1016/j.aca.2007.02.055

Ellwood, M.J., Hutchins, D.A., Lohan, M.C., Milne, A., Nasemann, P., Nodder, S.D., Sander, S.G., Strzepek, R., Wilhelm, S.W., Boyd, P.W., 2014. Iron stable isotopes track pelagic iron cycling during a subtropical phytoplankton bloom. Proc. Natl. Acad. Sci. USA. 112, E15-20. doi:10.1073/pnas.1421576112 
Fishwick, M.P., Sedwick, P.N., Lohan, M.C., Worsfold, P.J., Buck, K. N., Church, T. M., Ussher, S. J., 2014. The impact of changing surface ocean conditions on the dissolution of aerosol iron. Glob. Biogeochem. Cyc. 28 (11), 1235-1250. doi: 10.1002/2014GB004921

Fitzsimmons, J.N., Carrasco, G.G., Wu, J.F., Roshan, S., Hatta, M., Measures, C.I., Conway, T.M., John, S.G., Boyle, E.A., 2015. Partitioning of dissolved iron and iron isotopes into soluble and colloidal phases along the U.S. GEOTRACES North Atlantic Transect. Deep. Res. Pt II. 116, 130-151. doi: 10.1016/j.dsr2.2014.11.014

Hatta, M., Measures, C.I., Wu, J., Roshan, S., Fitzsimmons, J.N., Sedwick, P., Morton, P., 2015. An overview of dissolved Fe and Mn distributions during the 2010-2011 U.S. GEOTRACES North Atlantic cruises: GEOTRACES GA03. Deep Sea Res. Pt II. 116, 117-129. doi:10.1016/j.dsr2.2014.07.005

Henderson, G.M., Anderson, R.F., Adkins, J.F., Andersson, P., Boyle, E.A., Cutter, G., de Baar, H.J.W., Eisenhauer, A., Frank, M., Francois, R., Orians, K., Gamo, T., German, C.R., Jenkins, W.J., Moffett, J.W., Jeandel, C., Jickells, T.D., Krishnaswami, S., Mackey, D., Measures, C.I., Moore, J.K., Oschlies, A., Pollard, R., van der Loeff, M.R.D., Schlitzer, R., Sharma, M., von Damm, K., Zhang, J., Grp, S.W., 2007. GEOTRACES - An international study of the global marine biogeochemical cycles of trace elements and their isotopes. Chemie Der Erde-Geochemistry 67 (2), 85-131. doi:10.1016/j.chemer.2007.02.001

Homoky, W.B., John, S.G., Conway, T.M., Mills, R.A., 2013. Distinct iron isotope signatures and supply from marine sediment dissolution. Nat. Comm. 42143. doi: 10.1038/ncomms3143

Jenkins, W.J., Smethie, W.., Boyle, E.A., Cutter, G.C., 2015. Water mass analysis for the U.S. GEOTRACES North Atlantic Sections. Deep. Res. Pt II., 116, 6-20. doi: 10.1016/j.dsr2.2014.11.018

John, S.G., 2012. Optimizing sample and spike concentrations for isotopic analysis by double-spike ICPMS. J. Anal. At. Spectrom. 27, 2123-2131. doi:10.1039/c2ja30215b

John, S.G., Adkins, J.F., 2010. Analysis of dissolved iron isotopes in seawater. Mar. Chem. 119, 65-76. doi:10.1016/j.marchem.2010.01.001

John, S.G., Adkins, J.F., 2012. The vertical distribution of iron stable isotopes in the North Atlantic near Bermuda. Global Biogeochem. Cycles 26 (2). doi: 10.1029/2011GB004043

John, S.G., Mendez, J., Moffett, J.W., Adkins, J.F., 2012. The flux of iron and iron isotopes from San Pedro Basin sediments. Geochim. Cosmochim. Acta 93, 1429. doi:10.1016/j.gca.2012.06.003 
Klunder, M.B., Laan, P., Middag, R., de Baar, H.J.W., Bakker, K., 2012. Dissolved iron in the Arctic Ocean: Important role of hydrothermal sources, shelf input and scavenging removal. J. Geophys. Res. 117, C04014. doi:10.1029/2011JC007135

Labatut, M., Lacan, F., Pradoux, C., Chmeleff, J., Radic, A., Murray, J.W., Poitrasson, F., Johansen, A.M., Thil, F., 2014. Iron sources and dissolvedparticulate interactions in the seawater of the Western Equatorial Pacific, iron isotope perspective. Global Biogeochem. Cycles. 28, 1044-1065. doi: $10.1002 / 2014 \mathrm{~GB} 004928$

Lacan, F., Radic, A., Jeandel, C., Poitrasson, F., Sarthou, G., Pradoux, C., Freydier, R., 2008. Measurement of the isotopic composition of dissolved iron in the open ocean. Geophys. Res. Lett. 35, L24610, doi:10.1029/2008GL035841

Lacan, F., Radic, A., Labatut, M., Jeandel, C., Poitrasson, F., Sarthou, G., Pradoux, C., Chmeleff, J., Freydier, R., 2010. High-precision determination of the isotopic composition of dissolved iron in iron depleted seawater by double spike multicollector-ICPMS. Anal. Chem. 82, 7103-7111. doi:10.1021/ac1002504

Lutjeharms, E., 2006. The Agulhas Current. Springer Berlin Heidelberg, Berlin, Heidelberg.

Mawji, E., Schlitzer, R., Dodas, E.M., Abadie, C., Abouchami, W., Anderson, R.F., Baars, O., Bakker, K., Baskaran, M., Bates, N.R., Bluhm, K., Bowie, A., Bown, J., Boye, M., Boyle, E.A., Branellec, P., Bruland, K.W., Brzezinski, M., Bucciarelli, E., Buesseler, K., Butler, E., Cai, P., Cardinal, D., Casciotti, K., Chavez, J., Cheng, H., Chever, F., Church, T.M., Colman, A., Conway, T.M., Croot, P., Cutter, G., de Baar, H.J.W., de Souza, G., Dehairs, F., Deng, F., Dieu, H.T., Dulaquais, G., Echegoyen-Sanz, Y., Lawrence Edwards, R., Fahrbach, E., Fitzsimmons, J., Fleisher, M., Frank, M., Friedrich, J., Fripiat, F., Galer, S., Gamo, T., Solsona, E.G., Gerringa, L.J.A., Godoy, J., Gonzalez, S., Grossteffan, E., Hatta, M., Hayes, C.T., Heller, M.I., Henderson, G., Huang, K.-F., Jeandel, C., Jenkins, W.J., John, S., Kenna, T.C., Klunder, M., Kretschmer, S., Kumamoto, Y., Laan, P., Labatut, M., Lacan, F., Lam, P.J., Lannuzel, D., le Moigne, F., Lechtenfeld, O.J., Lohan, M., Lu, Y., Masqué, P., McClain, C.R., Measures, C., Middag, R., Moffett, J., Navidad, A., Nishioka, J., Noble, A., Obata, H., Ohnemus, D.C., Owens, S., Planchon, F., Pradoux, C., Puigcorbé, V., Quay, P., Radic, A., Rehkämper, M., Remenyi, T., Rijkenberg, M.J.A., Rintoul, S., Robinson, L.F., Roeske, T., Rosenberg, M., van der Loeff, M.R., Ryabenko, E., Saito, M.A., Roshan, S., Salt, L., Sarthou, G., Schauer, U., Scott, P., Sedwick, P.N., Sha, L., Shiller, A.M., Sigman, D., Smethie, W., Smith, G.J., Sohrin, Y., Speich, S., Stichel, T., Stutsman, J., Swift, J.H., Tagliabue, A., Thomas, A., Tsunogai, U., Twining, B.S., van Aken, H.M., van Heuven, S., van Ooijen, J., van Weerlee, E., Venchiarutti, C., Voelker, A.H.L., Wake, B., Warner, M.J., Woodward, E.M.S., Wu, J., Wyatt, N., Yoshikawa, H., Zheng, X., Xue, Z., 
Zieringer, M., Zimmer, L.A., 2015. The GEOTRACES Intermediate Data Product 2014. Mar. Chem. 177(1), 1-8. doi:10.1016/j.marchem.2015.04.005

Mead, C., Herckes, P., Majestic, B. J., Anbar, A. D., 2013. Source apportionment of aerosol iron in the marine environment using iron isotope analysis. Geophys. Res. Lett. 40(21), 1944-8007. doi: 10.1002/2013GL057713

Middag, R., Séférian, R., Conway, T.M., John, S.G., Bruland, K.W., de Baar, H.J.W., 2015. Intercomparison of Dissolved Trace Elements at the Bermuda Atlantic Time Series Station. Mar. Chem. 177(3), 476-479. doi:10.1016/j.marchem.2015.06.014

Moore, J.K., Doney, S.C., Glover, D.M., Fung, I.Y., 2001. Iron cycling and nutrientlimitation patterns in surface waters of the World Ocean. Deep Sea Res. Part II Top. Stud. Oceanogr. 49, 463-507. doi:10.1016/S0967-0645(01)00109-6

Nishioka, J., Obata, H., Tsumune, D., 2013. Evidence of an extensive spread of hydrothermal dissolved iron in the Indian Ocean. Earth Planet. Sci. Lett. 361, 26-33. doi:10.1016/j.eps1.2012.11.040

Noble, A.E., Echegoyen-Sanz, Y., Boyle, E.A., Ohnemus, D.C., Lam, P.J., Kayser, R., Reuer, M., Wu, J., Smethie, W., 2015. Dynamic variability of dissolved $\mathrm{Pb}$ and $\mathrm{Pb}$ isotope composition from the U.S. North Atlantic GEOTRACES transect. Deep Sea Res. Pt II. 116, 208-225. doi:10.1016/j.dsr2.2014.11.011

Ohnemus, D.C., Lam, P.J., 2015. Cycling of Lithogenic Marine Particulates in the US GEOTRACES North Atlantic Transect. Deep Sea Res. Part II Top. Stud. Oceanogr. Deep Sea Res. Pt II. 116, 283-302. doi:10.1016/j.dsr2.2014.11.019

Paul, M., van de Flierdt, T., Rehkämper, M., Khondoker, R., Weiss, D., Lohan, M.C., Homoky, W.B., 2015. Seawater Lead Isotopes Trace Agulhas Leakage. Geophys. Res. Lett. 42, 8515-8521. doi:10.1002/2015GL065625

Radic, A., Lacan, F., Murray, J.W., 2011. Iron isotopes in the seawater of the equatorial Pacific Ocean: New constraints for the oceanic iron cycle. Earth Planet. Sci. Lett. 306, 1-10. doi:10.1016/j.epsl.2011.03.015

Resing, J.A., Sedwick, P.N., German, C.R., Jenkins, W.J., Moffett, J.W., Sohst, B.M., Tagliabue, A., 2015. Basin-scale transport of hydrothermal dissolved metals across the South Pacific Ocean. Nature 523, 200-203. doi:10.1038/nature14577

Rijkenberg, M.J.A., Middag, R., Laan, P., Gerringa, L.J.A., van Aken, H.M., Schoemann, V., de Jong, J.T.M., de Baar, H.J.W., 2014. The distribution of dissolved iron in the West Atlantic Ocean. PLoS One 9, e101323. doi:10.1371/journal.pone.0101323

Rouxel, O.J., Auro, M., 2010. Iron Isotope Variations in Coastal Seawater Determined by Multicollector ICP-MS. Geostand. Geoanalytical Res. 34, 135- 
Saito, M.A., Noble, A.E., Tagliabue, A., Goepfert, T.J., Lamborg, C.H., Jenkins, W.J., 2013. Slow-spreading submarine ridges in the South Atlantic as a significant oceanic iron source. Nat. Geosci. 6, 775-779. doi:10.1038/ngeo1893

Schlitzer, R., eGEOTRACES - Electronic Atlas of GEOTRACES Sections and Animated 3D Scenes, http://www.egeotraces.org, 2015.

Sedwick, P.N., Church, T.M., Bowie, A.R., Marsay, C.M., Ussher, S.J., Achilles, K.M., Lethaby, P.J., Johnson, R.J., Sarin, M.M., McGillicuddy, D.J., 2005. Iron in the Sargasso Sea (Bermuda Atlantic Time-series Study region) during summer: Eolian imprint, spatiotemporal variability, and ecological implications. Global Biogeochem. Cycles 19, GB4006. doi:10.1029/2004GB002445

Sedwick, P.N., Sholkovitz, R., and Church, T. M., 2007. Impact of anthropogenic combustion emissions on the fractional solubility of aerosol iron:Evidence from the Sargasso Sea. Geochem. Geophys. Geosys. 8. 1525-2027 doi: 10.1029/2007GC001586

Siebert, C., Nagler, T.F., Kramers, J.D., 2001. Determination of molybdenum isotope fractionation by double-spike multicollector inductively coupled plasma mass spectrometry. Geochemistry Geophys. Geosystems 2. doi:10.1029/2000GC000124.

Staubwasser, M., Schoenberg, R., von Blanckenburg, F., Krüger, S., Pohl, C., 2013. Isotope fractionation between dissolved and suspended particulate $\mathrm{Fe}$ in the oxic and anoxic water column of the Baltic Sea. Biogeosciences 10, 233-245. doi:10.5194/bg-10-233-2013

Steele, R. C. J., Elliott, T., Coath, C. D., Regelous, M., 2011. Confirmation of massindependent $\mathrm{Ni}$ isotopic variability in iron meteorites. Geochim. et Cosmochim. Acta 75(24), 7906-7925. doi:10.1016/j.gca.2011.08.030

Villar, E., Farrant, G.K., Follows, M., Garczarek, L., Speich, S., Audic, S., Bittner, L., Blanke, B., Brum, J.R., Brunet, C., Casotti, R., Chase, A., Dolan, J.R., d'Ortenzio, F., Gattuso, J.-P., Grima, N., Guidi, L., Hill, C.N., Jahn, O., Jamet, J.-L., Le Goff, H., Lepoivre, C., Malviya, S., Pelletier, E., Romagnan, J.-B., Roux, S., Santini, S., Scalco, E., Schwenck, S.M., Tanaka, A., Testor, P., Vannier, T., Vincent, F., Zingone, A., Dimier, C., Picheral, M., Searson, S., Kandels-Lewis, S., Acinas, S.G., Bork, P., Boss, E., de Vargas, C., Gorsky, G., Ogata, H., Pesant, S., Sullivan, M.B., Sunagawa, S., Wincker, P., Karsenti, E., Bowler, C., Not, F., Hingamp, P., Iudicone, D., 2015. Ocean plankton. Environmental characteristics of Agulhas rings affect interocean plankton transport. Science 348, 1261447. doi:10.1126/science.1261447

Wu, J.F., Boyle, E.A., 2002. Iron In The Sargasso Sea: Implications for the processes 
controlling dissolved Fe distribution in the ocean. Global Biogeochem. Cycles 16(4), 1086. doi:10.1029/2001GB001453

Wyatt, N, J., Milne, A., Woodward, E.M.S., Rees, A.P., Browning, T.J., Bouman, H.A., Worsfeld, P.J., Lohan, M.C., 2014. Biogeochemical cycling of dissolved zinc along the GEOTRACES South Atlantic transect GA10 at $40^{\circ} \mathrm{S}$. Global Biogeochem. Cycles 28, 44-56. doi:10.1002/2013GB004637

Zhao, Y., Vance, D., Abouchami, W., de Baar, H.J.W., 2014. Biogeochemical cycling 952 of zinc and its isotopes in the Southern Ocean. Geochim. Cosmochim. Acta 125, 953 
Figure 1

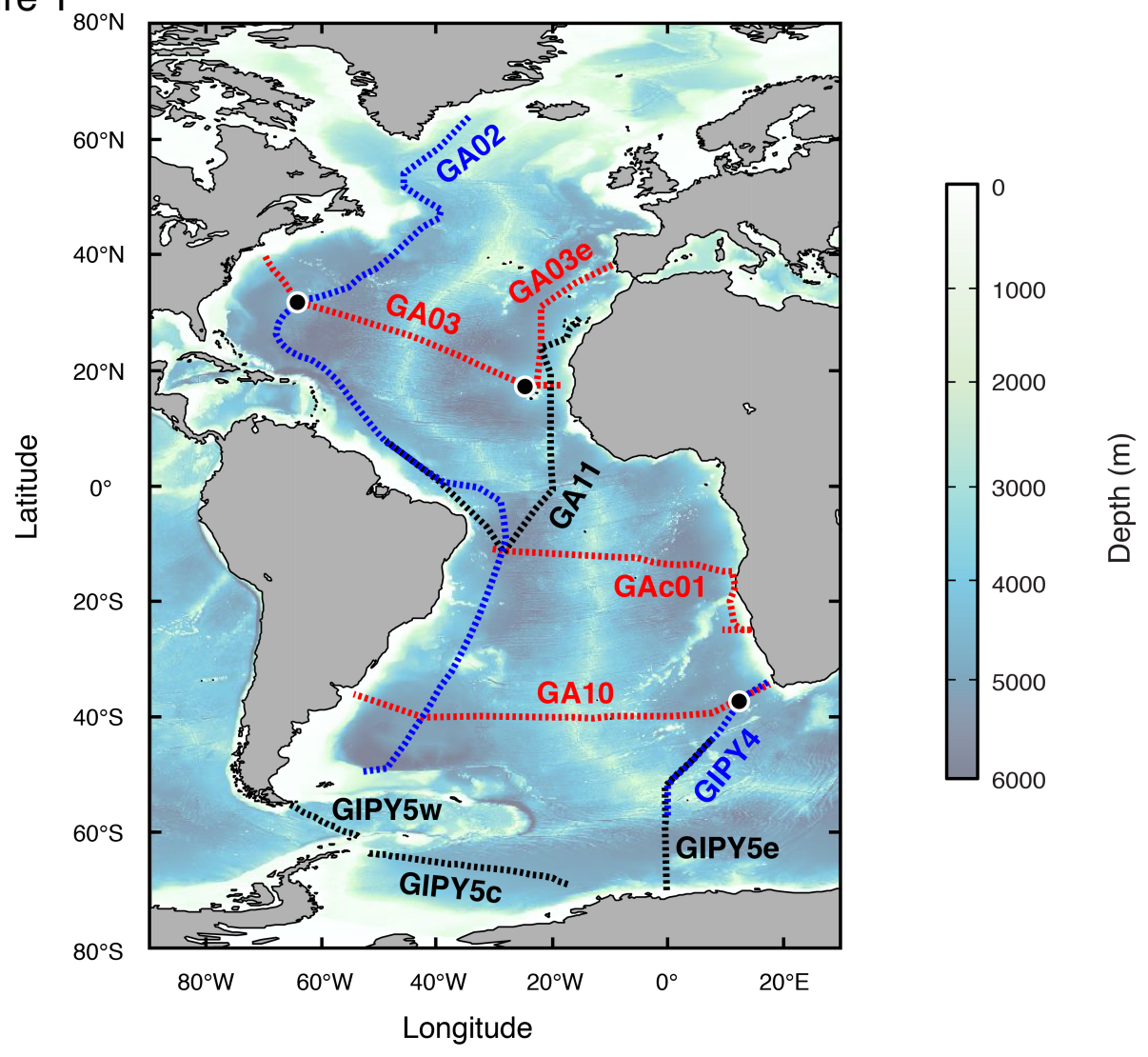




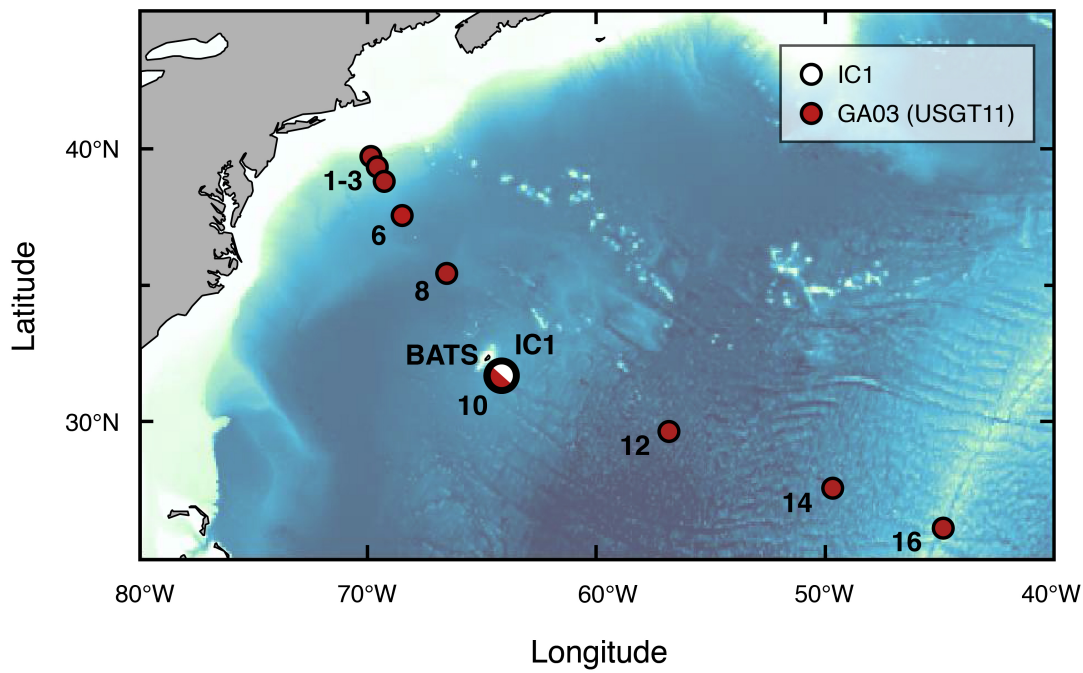

\section{b) BATS Water column}

Temperature $\left({ }^{\circ} \mathrm{C}\right)$

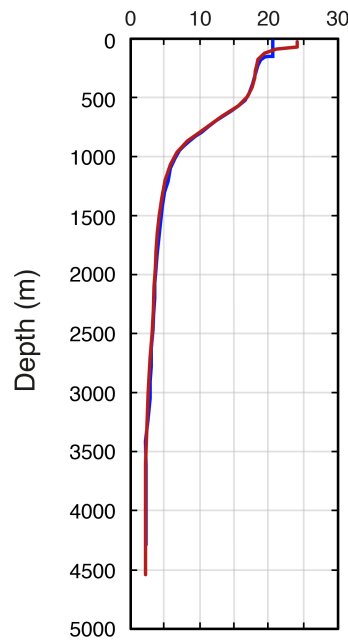

c) Surface (<10 m)
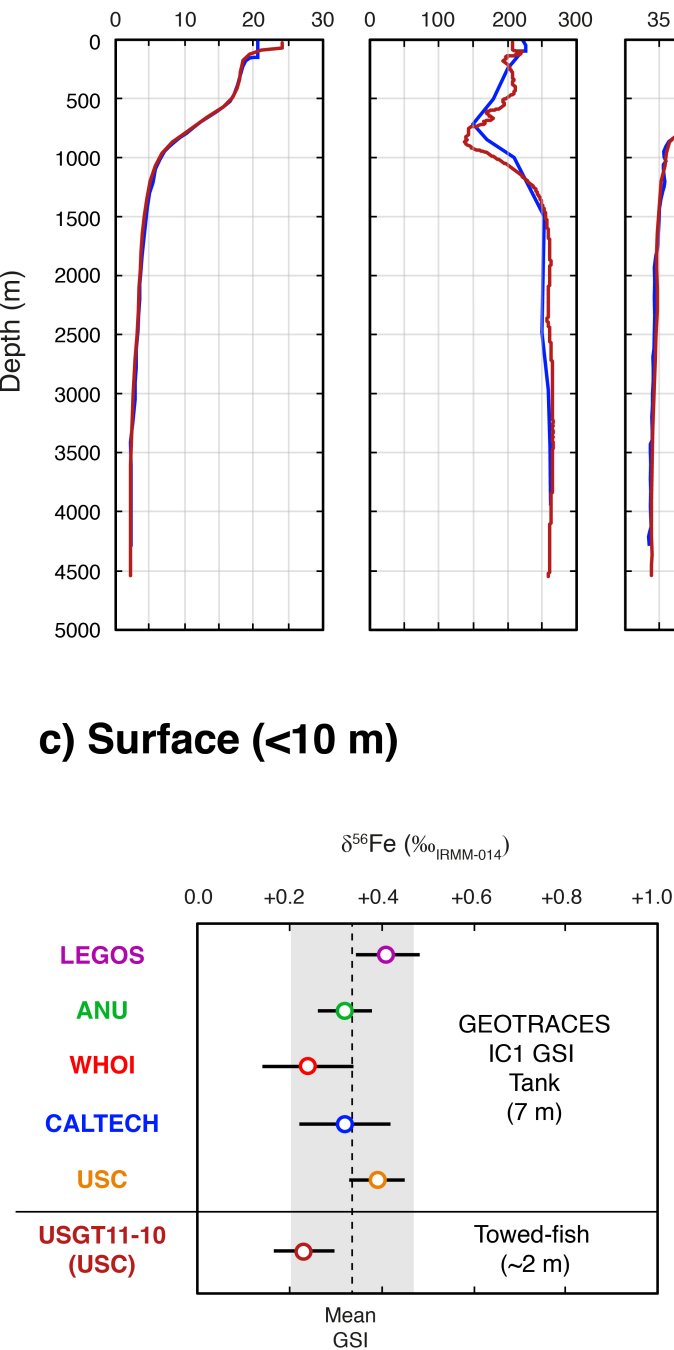

[Fe] $(\mathrm{nmol} \mathrm{kg-1})$

$\delta^{56} \mathrm{Fe}\left(\%_{\text {IRMM-014 }}\right)$
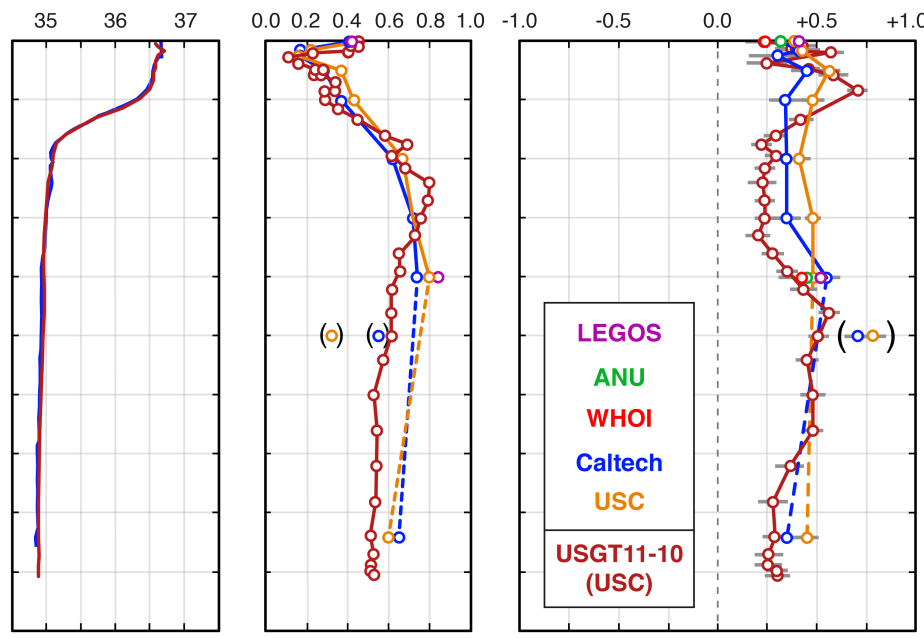

\section{d) Deep (1950-2100 m)}

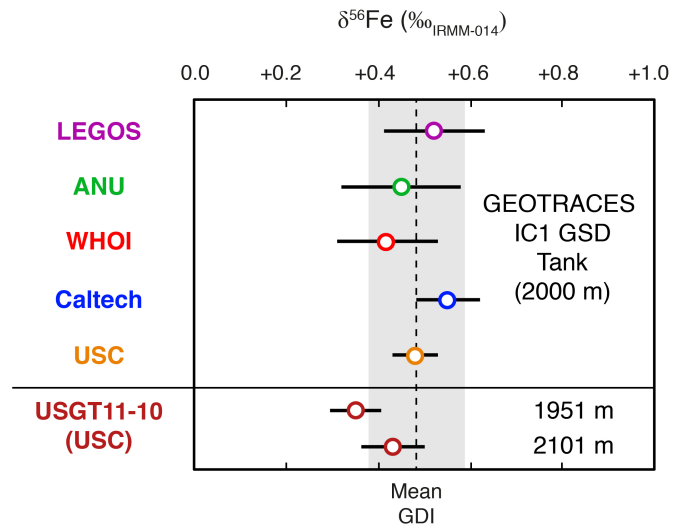




\section{a) Location Map}

Figure 3
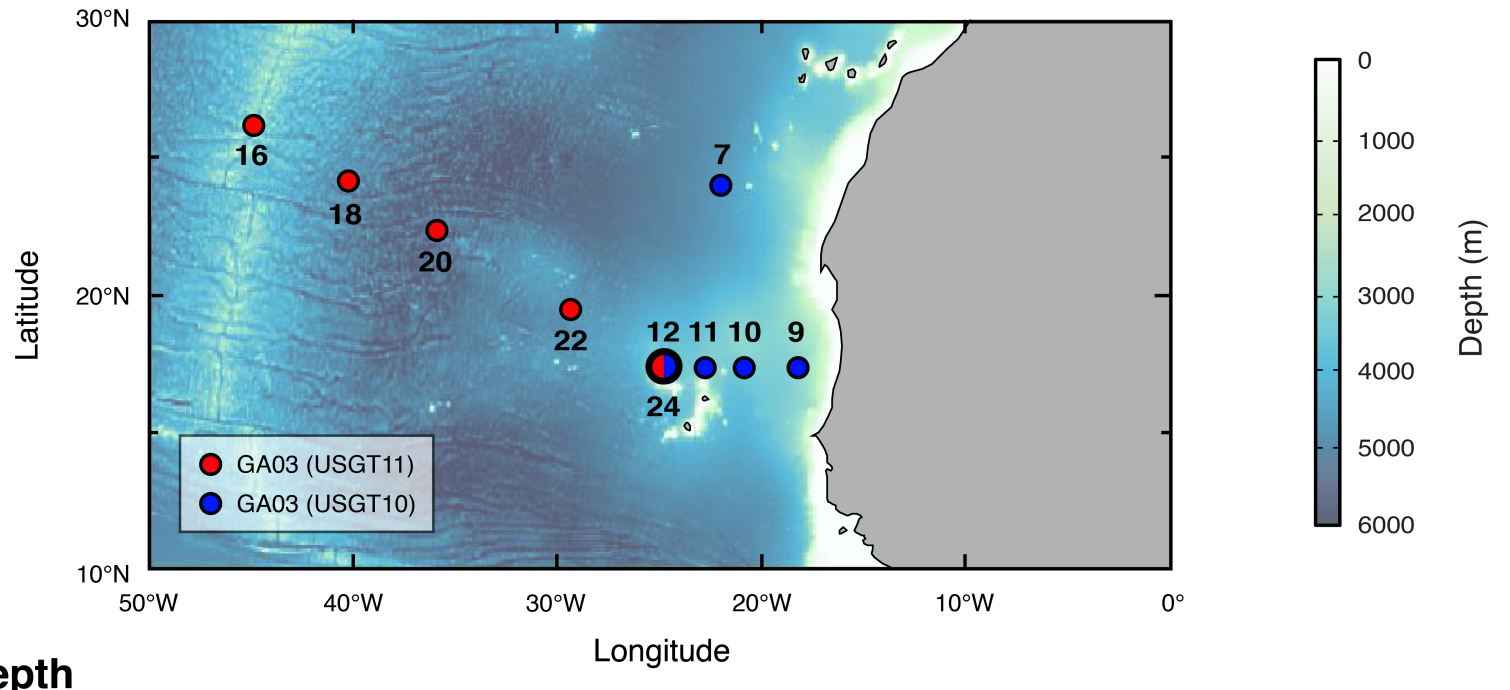

b) vs. Depth

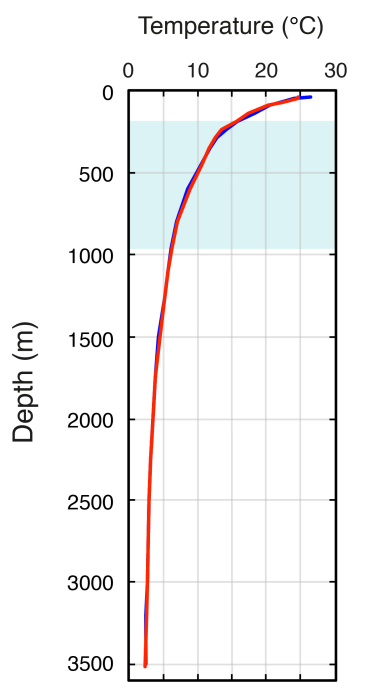

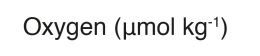
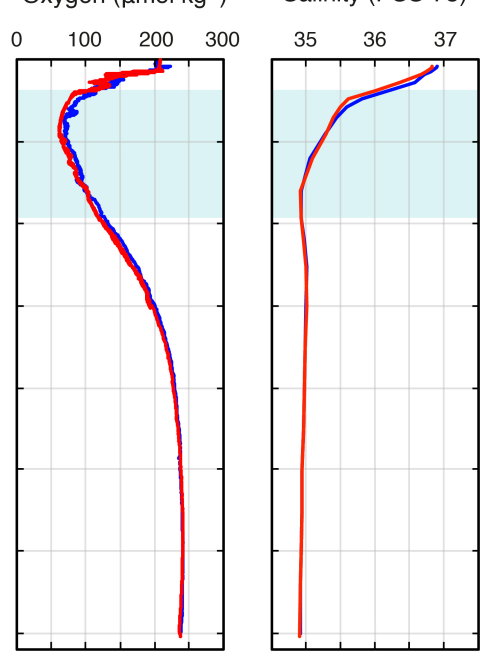

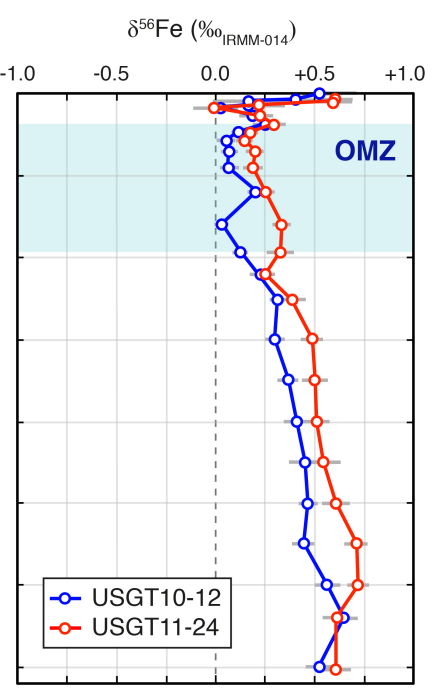

\section{c) vs. Density}

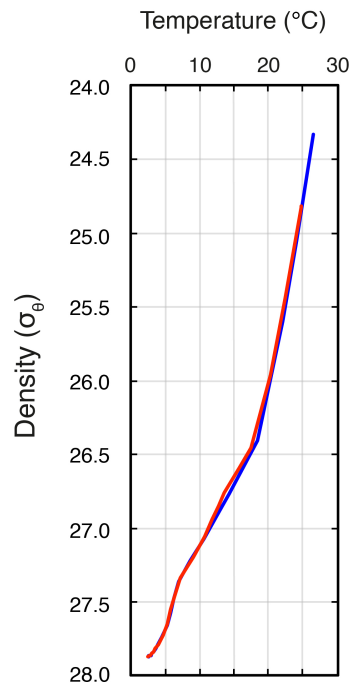

Oxygen ( $\mu \mathrm{mol} \mathrm{kg}^{-1}$ )
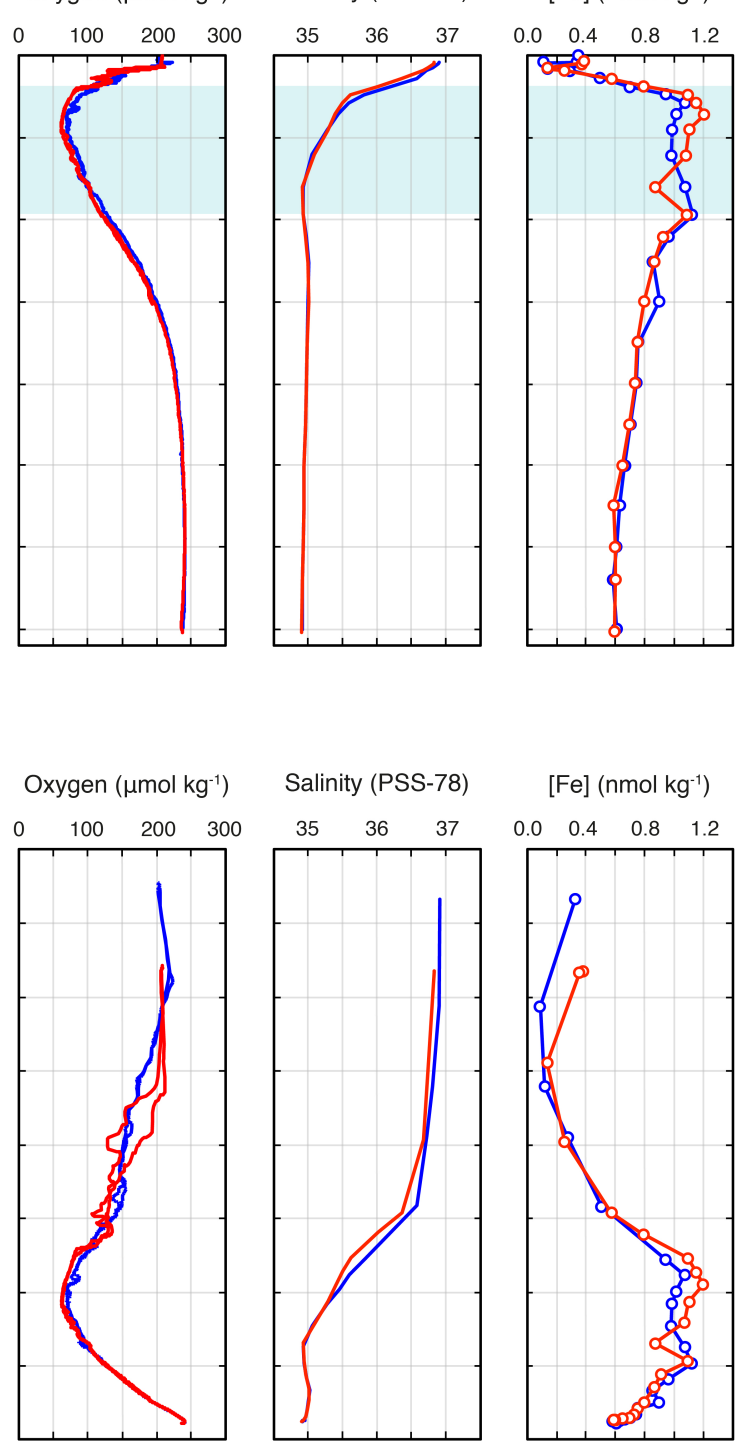

[Fe] (nmol kg-1)

$\delta^{56} \mathrm{Fe}\left(\% \mathrm{o}_{\text {IRMM-014 }}\right)$

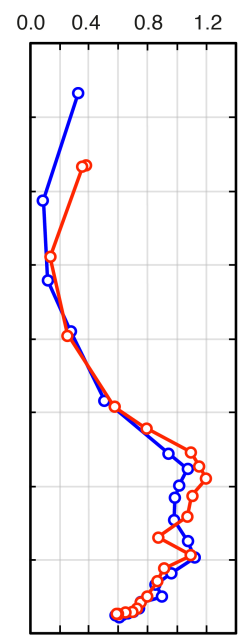

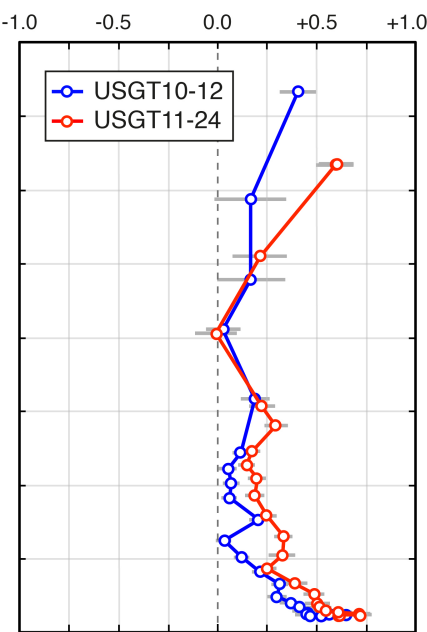




\section{a) Location Map}
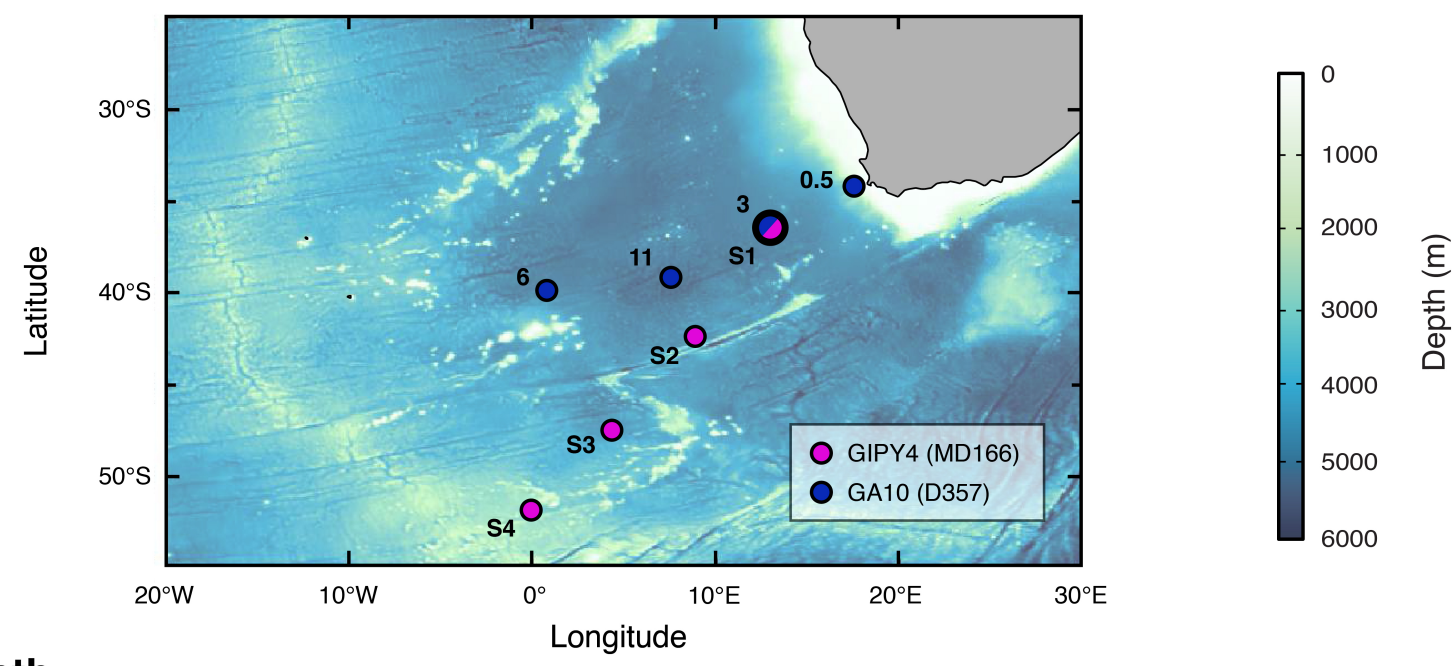

b) vs. Depth
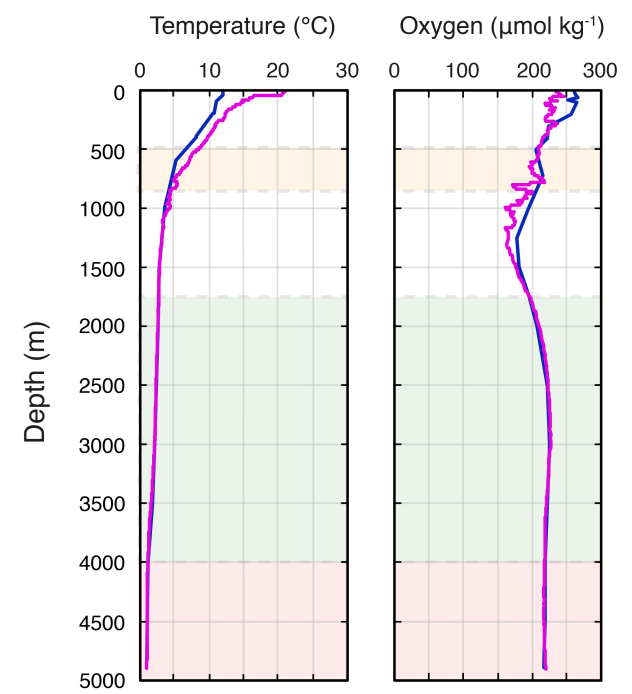

Salinity (PSS-78)

[Fe] $\left(\mathrm{nmol} \mathrm{kg}^{-1}\right)$

$\delta^{56} \mathrm{Fe}\left(\% 0_{\text {IRMM- } 014}\right)$
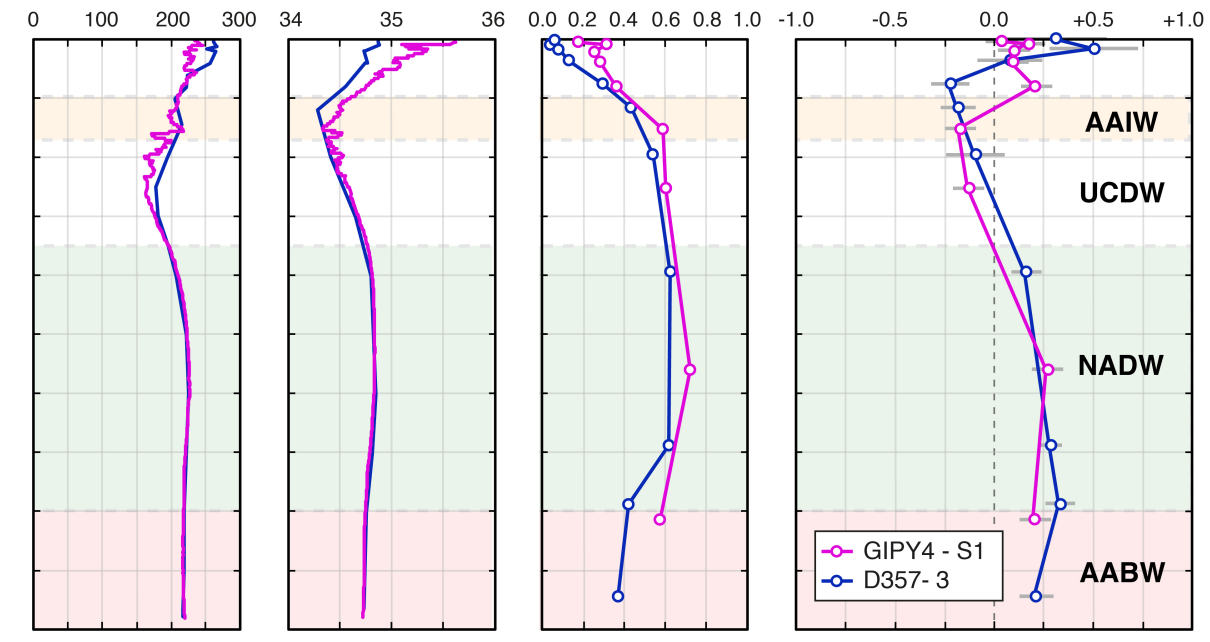

\section{c) vs. Density}

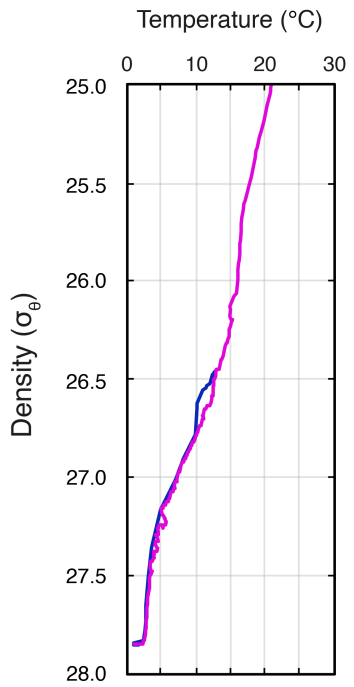

Oxygen $\left(\mu \mathrm{mol} \mathrm{kg}^{-1}\right)$

Salinity (PSS-78)

[Fe] $\left(\mathrm{nmol} \mathrm{kg}^{-1}\right)$

$\delta^{56} \mathrm{Fe}\left(\%_{\text {IRMM-014 }}\right)$
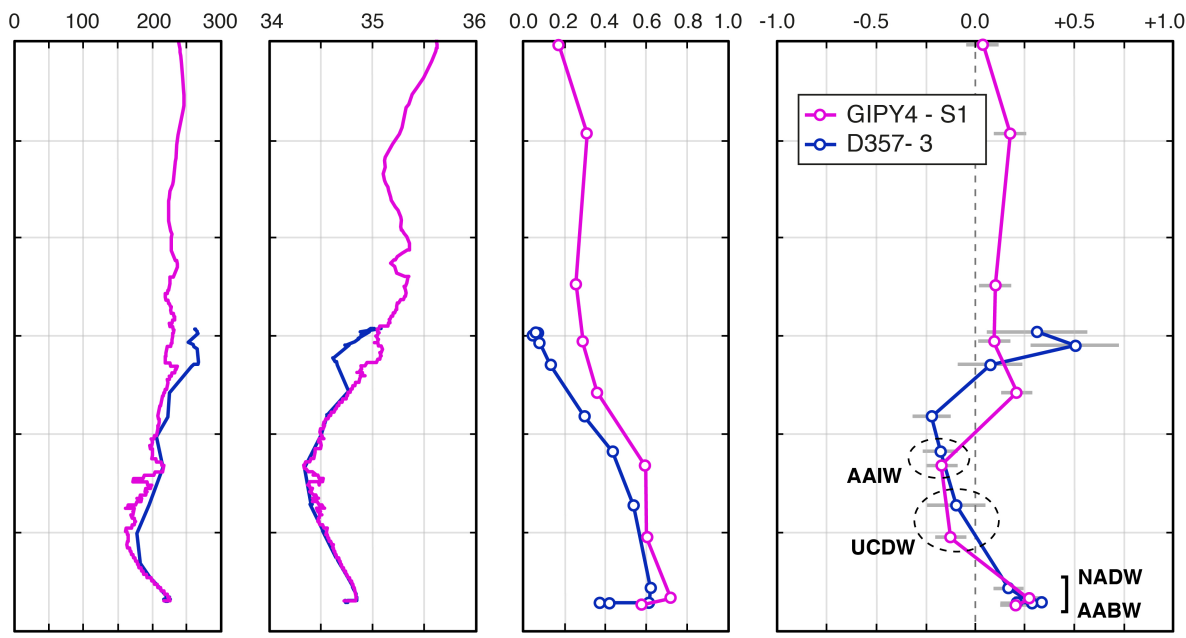